\title{
Quantification of Global Waste Heat and Its Environmental Effects
}

\author{
Anton Firth ${ }^{\mathrm{a}, 1}$, Bo Zhang ${ }^{\mathrm{a}, \mathrm{b},{ }^{*}}$, Aidong Yang ${ }^{\mathrm{a}}$
}

\section{Address}

aDepartment of Engineering Science, University of Oxford, Parks Road, Oxford OX1 3PJ, UK

bInstitute of Biomedical Engineering, Department of Engineering Science, University of Oxford, OX3 7DQ, UK

\section{Corresponding Author}

*Bo Zhang (bo.zhang@eng.ac.uk) 


\section{Abstract}

Waste heat is a major source of recoverable loss in societal energy use, offering significant potential for reduction in greenhouse gas emissions. A number of studies have been carried out to determine the size of the available resource but have been limited in scope or confined to the status quo. This work reports a method to quantify future global waste heat emissions from the Power Generation, Industry, Transport, and Buildings sectors, and investigates their environmental effects. Four projected energy landscapes (World Energy Outlook 2016: 1. Current Policies; 2. New Policies; 3. 450-scenario. 4. 100\% renewable energy penetration) were simulated to assess the amount of waste heat produced in different sub-sectors in the year 2030. The impact of $\mathrm{CO}_{2}$ radiative forcing and various technological shifts are reported. Total waste heat emissions are found to account for 23.0$53.0 \%$ of global input energy depending on year and scenario, with a range of theoretical and economic recovery potentials of $6-12 \%$ and $6-9 \%$ respectively. Further insight is gained into the waste heat landscape through analysis of temperature and sectoral distributions, and identification of hotspots for targeted waste heat recovery. When considering emissions from 2014 to 2030, the integrated radiative forcing of $\mathrm{CO}_{2}$ is found to be 13 times greater than that of waste heat, primarily attributable to the former's cumulative nature. Full recovery of the theoretical potential is found to lead to a $10-12 \%$ reduction in the combined forcing of $\mathrm{CO}_{2}$ and waste heat over this period, mainly due to a reduction in $\mathrm{CO}_{2}$ emissions. Under a conservative carbon tax, this reduction is estimated to offer potential economic savings of $\$ 20-77 \mathrm{bn} /$ year. A $10 \%$ increase in the penetration of solar/wind/tidal hydroelectric power and electric vehicles are found to decrease global waste heat losses in liquid and gaseous streams by $5 \%$ and $0.7-2.0 \%$, respectively; retrofitting of Carbon Capture and Storage to power plants decreases $\mathrm{CO}_{2}$ radiative forcing, outweighing the increase in thermal radiative forcing from additional waste heat streams. 


\section{Keywords}

Waste Heat Quantification; Global Waste Heat; Energy Flow; Global Efficiency; Radiative Forcing 


\section{Highlights}

- $\quad 49.3-51.5 \%$ of global energy use would end up as waste heat in 2030.

- Transport sector accounts for the largest (43\%) recoverable waste heat in 2030.

- Economically recoverable waste heat is substantial even without carbon tax.

- Radiative forcing of waste heat is quickly surpassed by that of associated $\mathrm{CO}_{2}$. 


\section{Glossary}

- AHF: Anthropogenic Heat Flux.

- CCS: Carbon Capture and Storage.

- EL: Effluent/Exhaust Losses. Thermal energy contained in liquid and gaseous output material streams of a process.

- ES: Energy Services. Useful work delivered by a process.

- EV: Electric Vehicle.

- FCEV: Fuel Cell Electric Vehicle.

- HHV: Higher Heating Value.

- IWH: Industrial Waste Heat.

- LHV: Lower Heating Value.

- Other Losses (OL): Sum of energetic losses of a process, other than EL.

- WHR: Waste Heat Recovery.

- WWS: Wind, Water, and Solar power. 


\section{Introduction}

Substantial effort is being put into decarbonisation of the global energy mix to reduce the anthropogenic contribution to the greenhouse effect. However, there is also significant potential for reduction in $\mathrm{CO} 2$ emissions from improvements in energy efficiency; global exergy efficiency from production of fuels to final consumption was estimated to be $11 \%$ in a 2010 study [1]. Part of the energetic losses becomes unrecovered thermal energy contained within material output streams of processes, which has often been referred to "waste heat". However, this concept has not been objectively defined, and in theory could encompass all energetic losses. Clear definition and quantification of waste heat that can be avoided or utilised are thus essential in order to drive commercial investments into Waste Heat Recovery (WHR) and affect future energy policy.

There has been much research into waste heat quantification, ranging from small-scale reviews of individual sites to global estimates. As described by Brueckner et al, there are two main ways of carrying out such waste heat quantification investigations: bottom-up and topdown [2]. The former involves combining data from sub-systems to characterise a system. The latter involves applying a general methodology to an entire system and breaking down the results to investigate sub-systems, refining the methodology if necessary. In addition, there are three broad methods of waste heat quantification:

- Thermodynamics-based analysis, which calculates the enthalpy of specific waste heat streams. Figures are obtained from emissions databases and tabulated process stack temperatures, which are obtained via surveys for specific plants, or estimated for general processes.

- Efficiency-based analysis, which estimates the current average efficiency of various technologies and processes, and calculates the potential energy savings from upgrading to a new efficiency (often estimated best-practice). 
- Coefficient-based analysis, which refers to the development of subsystem-specific coefficients for the ratio of waste heat to some easily measurable quantity, typically [waste heat]:[energy input] or [waste heat]:[ $\mathrm{CO}_{2}$ emissions]. The possibility of transferring such ratios to different regions than those they were originally developed for is investigated in the work of Miró et al [3].

There are four main types of results obtained from these analyses: total waste heat, theoretical potential (waste heat that is thermodynamically recoverable), technical potential (waste heat that is feasibly recoverable), and the economic potential (waste heat that is economically favourable to recover). As expected, each is a subset of the former. In terms of scope, only liquid and gaseous waste heat streams are typically covered, and most studies focus on national Industrial Waste Heat (IWH), often relying on surveyed data from a number of large facilities. The number of global analyses is very limited: only one global waste heat quantification study was found, in addition to several global energy and exergy flow studies which investigate general process efficiency and quantify overall losses.

A 2008 U.S. Department of Energy investigation into U.S. IWH focussed on the most energy-intensive industries in a top-down, thermodynamics-based study [4]. The typical proportion of energy input lost as flue gas waste heat was estimated for a number of processes. Using estimated energy input and flue gas exhaust temperature for each process, it was then possible to calculate the waste energy and exergy. A theoretical potential of $18 \%$ of input energy was found, with an overall technical potential of around $7 \%$ but ranging between $5-33 \%$ in the investigated sub-sectors. One of the most important studies on the topic of global efficiencies is in an energy flow study by Nakicenovic in 1996 [5]. Using data from literature, exergy efficiency values were assigned to various fuels, processes, and technologies. Combined with energy flow data, losses were quantified at several stages between primary energy provision and final consumption. Global energy efficiency was found to be $29 \%$, and exergetic efficiency around $10 \%$. However, the waste heat recovery potential was not considered. In 2010, Cullen and Allwood's built upon the work of Nakicenovic by classifying overall losses into 10 mechanisms [1]. Using updated 
efficiency values, global exergetic efficiency was thus found to be $11 \%$, marginally higher than Nakicenovic's paper which was published 14 years earlier. In 2016, Forman et al. conducted what appears to be the only global waste heat quantification study, using a mix of efficiency- and thermodynamics-based analysis in a top-down approach [6]. Using global energy flow data, an energy balance was performed on each conversion process, with efficiency factors either estimated or largely derived from the investigations of Nakicenovic, and Cullen and Allwood. The overall quantity of waste heat was first calculated, then converted into a theoretical potential using the Carnot efficiency. Results were split into five sectors: industrial, commercial, residential, transport, and electricity generation. Overall, it was found that approximately $72 \%$ of global energy input was lost through the conversion processes investigated, with waste heat accounting for $52 \%$ of input energy. The global theoretical potential was found to be $10 \%$ of input.

Research into the global environmental effects of waste heat is fairly limited. However, more is reported on the global environmental effects of Anthropogenic Heat Flux (AHF), i.e. the total heat flux caused by human activities. The methodologies used to quantify AHF and its effects can therefore be transferred to waste heat flux. Quantification results are often expressed in terms of radiative forcing, defined as the radiation imbalance of the Earth due to a perturbation, as measured at the tropopause [7]. It may therefore be considered a measure of the net amount of energy entering the Earth's energy system due to this perturbation. For the year 2011 , the total radiative forcing due to all greenhouse gases in the Earth's atmosphere (i.e. ignoring water vapour) was estimated to be $2.83 \mathrm{~W} / \mathrm{m}^{2}$, of which $1.82 \mathrm{~W} / \mathrm{m}^{2}$ was due to $\mathrm{CO}_{2}$ [7]. In 2009, Flanner argued for the inclusion of AHF in global climate models due to its significant influence on local climate [8]. Averaged over the planet, AHF was found to lead to a relatively modest radiative forcing of $0.028 \mathrm{Wm}^{-2}$. However, in reality AHF emanates from regions of human activity, and was determined to be significantly affect local climate in areas where radiative forcing exceeded $3 \mathrm{Wm}^{-2}$. One emissions scenario predicted annual mean warming due to $\mathrm{AHF}$ of $0.4-0.9^{\circ} \mathrm{C}$ over large industrialised 
regions by 2100 . The radiative forcing effects of waste heat and $\mathrm{CO}_{2}$ emissions from power plants were compared by Zevenhoven in 2011 [9]. Global waste heat emissions from power plants were estimated from assumed thermal efficiencies, and only the effects of emissions after 2005 were investigated, i.e. ignoring the forcing due to $\mathrm{CO}_{2}$ already present in the atmosphere. The accumulation of $\mathrm{CO}_{2}$ led to rapidly increasing radiative forcing that quickly became more important than that of the estimated thermal emissions, equalling it in around 5 weeks. In 2015, Zhang and Calderia expanded upon the work of Zevenhoven, comparing the effects of thermal and $\mathrm{CO}_{2}$ radiative forcing for all fossil fuel use [10]. Through the same approach it was shown that forcing from $\mathrm{CO}_{2}$ associated with coal, oil, and gas combustion exceeded the related thermal forcing after 34 days, 45 days, and 59 days respectively.

Several widespread problems became apparent following analysis of current literature. The first was a lack of clear or consistent methodologies in waste heat quantification. Different authors made different sets of assumptions (such as baseline temperatures for exergetic analysis, usually either $25^{\circ} \mathrm{C}$ or $\left.150^{\circ} \mathrm{C}[4,6,11]\right)$ which were not always explicitly stated, and often did not reveal the process behind the given results. The second was a lack of process data for much of the world. This can be due to poor administration in various regions, as well as an unwillingness of companies to reveal sensitive data. Consequently, process data is either estimated or self-reported through surveys, which is likely to lead to inaccuracy. Waste heat quantification was also found to be spatially and temporally limited: there was a lack of global studies, and previous analyses were all for the present-day and did not look into the future. Due to the current rate of change of the global energy mix, analysis of the status quo may be limited in its usefulness when considering the abatement potential of waste heat in the foreseeable future. Lastly, there appeared to be no analysis of the environmental effects of waste heat based on in-depth waste heat quantification at a global scale. 
This work aims to quantify global waste heat in a broad range of sectors, for the present day and the future until 2030. This is combined with an assessment of the environmental effects of such waste heat streams. More specifically, the term 'waste heat' will be taken to mean thermal energy contained within effluent and exhaust streams, i.e. liquid and gaseous outputs, which dissipates into the environment without fulfilling any useful purpose. Due to limited available data and the relative uncommonness of solid WHR, solid streams are not included in this study despite their reported significance [12]. The only environmental effects investigated are in terms of global heat flux. This paper first presents the methodologies used to quantify overall and recoverable waste heat, and their environmental effects. Following this, results are presented and then analysed. Finally, possible future work and improvements are suggested. 


\section{Methodology}

Waste heat quantification is carried out for the years 2014 and 2030 by applying processspecific factors to existing present and future energy flow data. The environmental effects associated with the predicted waste heat are then determined, in terms of radiative forcing.

\subsection{Waste Heat Quantification}

\subsubsection{Overview}

The global scale of this investigation meant a top-down approach was required with a strong degree of aggregation. The methodology of Forman et al. [6] was used and modified where appropriate; this was due to its ease of use and recentness.

In this methodology, the global energy system is viewed as an open system, shown

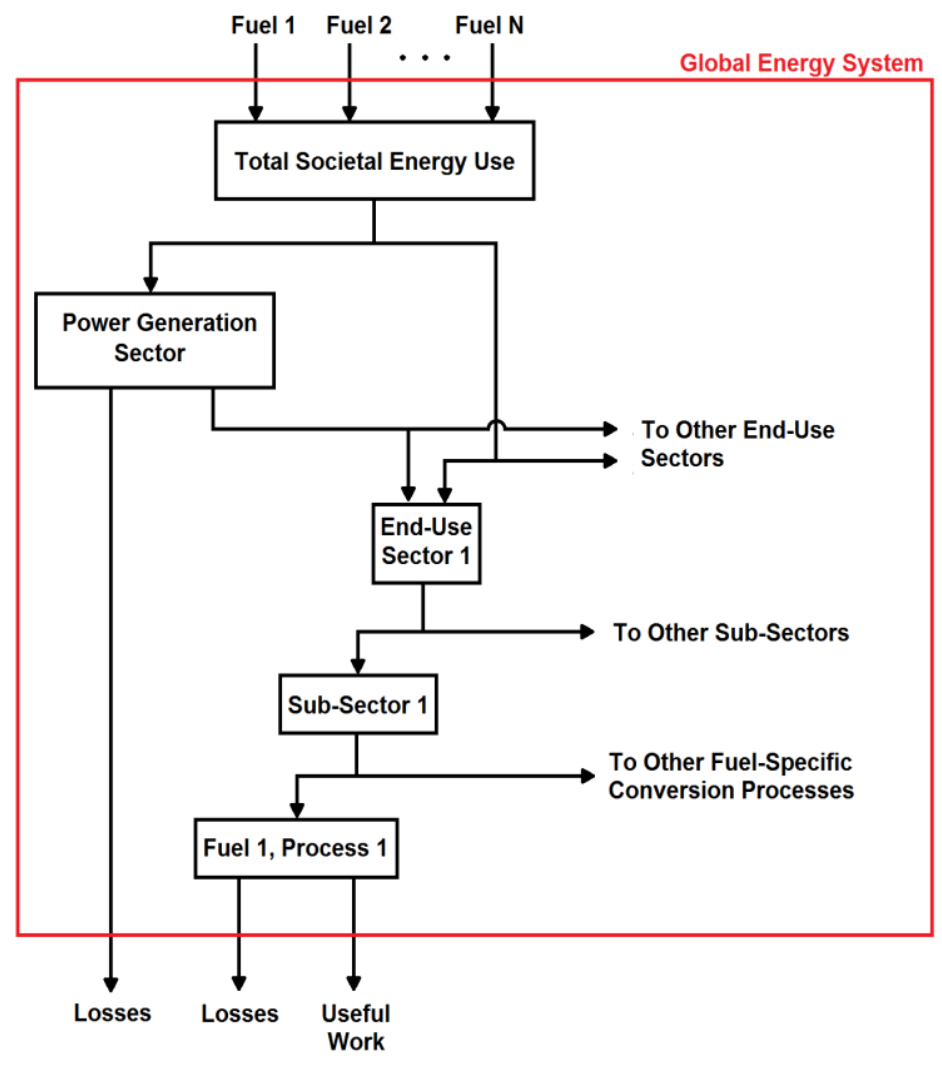

Figure 1: Model of global energy system graphically in Fig. 1. Total societal energy use is input in the form of several different fuel types (e.g. coal, oil), flows through the system, and is divided into sectors and then sub-sectors. Within sub-sectors, energy undergoes fuel-specific conversion processes, through which it is removed from the system as useful work and losses, or is converted into a different type of energy flow. There are two types of sector: end-use sectors, where all input energy is removed 
from the system, and the Power Generation sector, where energy is converted from one form to another with associated losses.

Processes are analysed by dividing their output energy into three categories:

- Energy Services (ES): useful energy delivered by the process

- Effluent and Exhaust Losses (EL): rejected thermal energy contained in effluents and exhausts (liquid and gaseous output material streams)

- Other Losses (OL): other rejected energy (e.g. losses due to transmission, friction, radiation)

In order to calculate the proportion of input energy converted into each category (ES, EL and OL), 'balance factors' are used: $\eta_{\mathrm{es}}, \eta_{\mathrm{el}}, \eta_{\mathrm{ol}}$. These are applied to input energy in the same manner as efficiencies (e.g. OL $=$ input $\left.^{\star} \eta_{\mathrm{ol}}\right)$. This is presented graphically in Fig. 2.

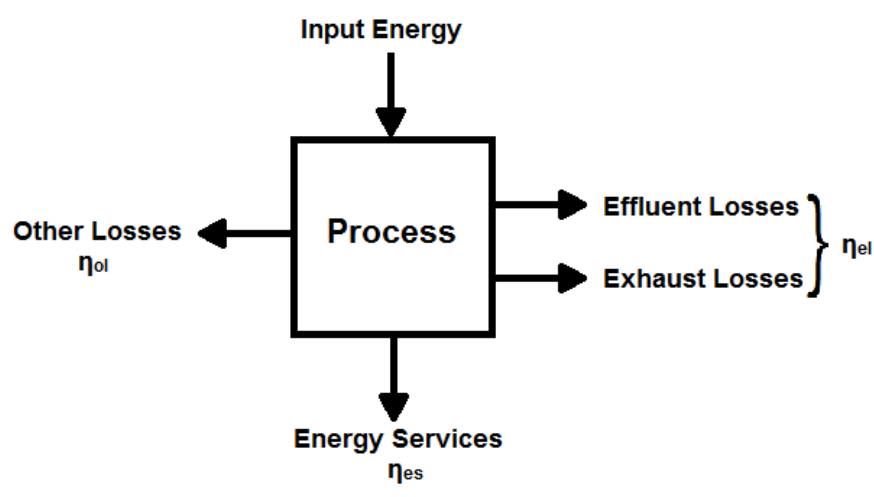

Figure 2: Classification of process output energy, adapted from [2].
The term 'waste heat' is taken to only encompass thermal energy contained in process effluents and exhausts (EL waste). However, the energetic value offers no indication of the quality of the wasted heat, only the quantity. A more useful concept is that of the waste heat's exergy, i.e. the maximum amount of work that can be extracted from the streams with a given environmental temperature $\left(T_{\text {sink }}\right)$. This is obtained by multiplying the energetic content of a waste heat stream with the Carnot factor (Eq. 3.1), which calculates the exergetic value of the waste heat available at a temperature of $T_{\text {source }}$. This quantity is adopted as a unified measure of the theoretical potential of the waste heat recovery from various streams. 


$$
\eta \text { Carnot }=1-\frac{\mathrm{T}_{\text {sink }}}{\mathrm{T}_{\text {source }}}
$$

Using the terminology of Cullen and Allwood [1], only active energy conversion processes, which convert energy into more useful forms, are covered by this methodology. Passive processes where useful energy is lost are not considered. This is due to the difficulty in determining efficiencies for passive systems from which to derive balance factors; and because wasted heat from such systems is likely to be at very low temperatures and thus have low exergy.

There was only one major change to this general methodology: when calculating the exergy content of EL streams with an environmental temperature of $25^{\circ} \mathrm{C}$, the Higher Heating Value (HHV) of fuels was used rather than Lower Heating Value (LHV). For further explanation, see Appendix A-1.

\subsubsection{Data Sources}

\section{Energy Flow Data}

Energy flow data are those of individual fuel-specific energy streams through each sector and sub-sector. In this work, they were sourced from the International Energy Agency (IEA). The IEA's comprehensive database and long history of producing this type of data meant they were considered a reliable source.

Past and present energy flow data were taken from the IEA's annual World Balance Sankey Diagram [13]. This presents global fuel-specific energy flow data from primary energy to final consumption in sub-sectors. Many of these sub-sectors correspond to aggregations of classes or descriptions given by the Industrial Standard Classification of All Economic Activities (ISIC) [14]. Future energy flow data was obtained from the IEA's World Energy Outlook 2016 (WEO), where data is provided in a similar format, but only to a sectoral level [15]. 
Table 1: Sectors and Sub-sectors Investigated, adapted from Forman et al. [6].

\begin{tabular}{|l|}
\hline Sector/Sub-sector \\
\hline Industry \\
Iron and Steel \\
Chemical and Petrochemical \\
Non-Ferrous Metals \\
Non-Metallic Minerals \\
Transport Equipment \\
Machinery \\
Mining and Quarrying \\
Food and Tobacco \\
Paper, Pulp and Print \\
Wood and Wood Products \\
Construction \\
Textile and Leather \\
Agriculture and Forestry \\
Fishing \\
Non-Specified Industry \\
\hline Buildings \\
Residential \\
Commerce and Public Services \\
Non-Specified Other \\
\hline Transport \\
Road \\
Rail \\
Pipeline Transport \\
Aircraft \\
Shipping \\
Non-Specified Transport \\
\hline Power Generation \\
\hline
\end{tabular}

The IEA's pre-existing definitions of sub-sectors were adopted due to the existence of a corresponding database of process-specific data. The only energy flows excluded in this work were the "Non-Energy Use" sector (i.e. feedstocks), and the "Other Transformations" and "Refineries" processes, due to a lack of required data. The sub-sectors covered in this analysis, and their aggregation into sectors, are shown in Table 1.

It should be noted that the Aircraft and Shipping subsectors are both aggregations of two smaller subsectors, and that the Agriculture and Forestry sub-sector and the Fishing sub-sector have both been included in the Industry sector in this study.

As previously stated, future energy flow data was taken from the WEO, which gives estimates for future energy use according to several different scenarios. These scenarios are derived from the projections of

current global trends and policies and do not account for the risk of disruptive change in technology or policy, and are considered the 'main' scenarios in this study:

- Current Policies (CP): assumes that no new legislation is implemented from mid2016 onwards, thereby ignoring any policies that have already been planned but not implemented. Whenever a range of targets exists, the least ambitious is selected.

- New Policies (NP): incorporates legislation that is already in place, as well as legislation and targets that have been committed to but not yet implemented as of mid-2016. The likelihood of success of the latter (in terms of time and results) is evaluated on a case-by-case basis. 
- 450: based on limiting the average global temperature increase by 2100 to $2^{\circ} \mathrm{C}$ above industrial levels, by limiting the atmospheric $\mathrm{CO}_{2}$ concentration to $450 \mathrm{ppm}$.

In addition to this, a fourth scenario with aggressive renewable penetration (termed the Aggressive scenario) was derived from the work of Jacobson and Delucchi [16], [17]. In this case, all electricity is generated from Water, Wind, and Solar power (WWS), leading to electrification of the majority of end-use processes, while delivering the same total Energy Services in each sub-sector as in the CP scenario. However, while Jacobson's work assumes electrolytically-generated hydrogen was used to replace fossil fuels where electrification was not feasible, this scenario assumes such fossil fuel use continued. This scenario corresponds to an ambitious overhaul of global energy use, and is not the main focus of this study.

\section{Process Data}

Sub-sectors are simplified by assuming they comprise a small number of representative processes. Each of these processes will have associated balance factors, exhaust/effluent temperatures, and fraction of the sub-sectoral energy used. This is compiled for each different fuel input into each subsector. All of this information allows the energetic and exergetic analyses to take place. Such process data was taken from the tables of Forman et al., where they were compiled from literature, assumption, energy balance (i.e. all balance factors sum to 1), calculation, or estimation [2]. An example is given in Table 2. Certain balance factors have been updated from the work of Forman et al.[6], and are provided in Appendix A-2.

Table 2: Natural Gas Input Into the Chemical and Petrochemical Sub-sector [2]

\begin{tabular}{|l|l|l|}
\hline $\begin{array}{l}\text { Process/Equipment, } \\
\text { Split }\end{array}$ & $\begin{array}{l}\text { Balance Factors } \\
\left(\boldsymbol{\eta}_{\mathrm{es}}, \boldsymbol{\eta}_{\mathrm{el}}, \boldsymbol{\eta}_{\mathrm{ol}}\right)\end{array}$ & $\begin{array}{l}\text { Exhaust/Effluent Phase, Split, } \\
\text { Temperature (same for both) }\end{array}$ \\
\cline { 1 - 2 } Gas Burner, 50\% $[\mathrm{A}]$ & $64 \%[1], 26 \%[\mathrm{~A}], 10 \%[\mathrm{~A}]$ & Gas, 95\% $[\mathrm{B}], 150^{\circ} \mathrm{C}[4]$ \\
\cline { 1 - 2 } Steam Reformer, 50\% $[\mathrm{A}]$ & $80 \%[27,28], 10 \%[\mathrm{~B}], 10 \%[\mathrm{~A}]$ & Liquid, 5\% $[\mathrm{A}], 85^{\circ} \mathrm{C}[4]$ \\
\hline
\end{tabular}

$[\mathrm{A}]$ : Assumption; [B]: Energy Balance 


\subsection{Estimating Future End-Use Energy Flow Data}

The waste heat quantification methodology used in end-use sectors required fuel-specific sub-sectoral energy flow data. While the IEA's Sankey Diagram provided past and present data in this format, the future data provided in the WEO only gave fuel-specific energy flows to a sectoral level. Using historical sub-sectoral data, it was found that the proportion of sectoral energy consumed by each sub-sector, and the 'fuel split' within each sub-sector had either remained relatively constant or followed relatively linear trends over the last 10 years of available data. Due to the availability of past sub-sectoral data for guidance and reasonably predictable trends, it was decided to estimate future sub-sectoral data through trend extrapolation. Further detail is provided in Appendix A-3.

All extrapolations were performed using a first-order, least-squares line of best fit for 10 year historical data. Values obtained were not allowed to decrease to below $0 \%$, and all splits were normalised if necessary to ensure they summed up to $100 \%$. In some cases, such as those with erratic or weak trends, the general linear F-test [20] was used to determine whether a linear extrapolation or a simple 10-year mean value is more appropriate.

\subsection{Estimating Future Power Generation Energy Flow Data}

The data used for the power generation balance factors is in a slightly different format to other sectors, and as a result the methodology used is also slightly different. There are 3 areas of loss: thermodynamic losses during the power generation cycle, auxiliary losses (including electricity needed to run the pumps, compressors, etc.), and transmission and distribution losses. The first of these was taken to constitute EL, while the latter two were combined to make up OL. For further information, see Appendix A-4.

In the IEA data, "solar/wind/tide" and hydroelectric data are given as the value of generated electricity, and therefore have no quantified losses associated with generation. 
Thus, the only losses for these power generation systems were due to transmission and distribution.

The accuracy of chosen balance factors can be evaluated by comparing estimated final output power with actual final output power, i.e. the sum of heat and electricity inputs to all sectors. While this does not explicitly give an error of waste heat estimates, it does provide a substantial measure of quality. If useful energy output is correctly predicted, then all that remains uncertain is the accuracy of the EL:OL ratio. Errors are presented in Table 3, where negative values represent an underestimate of generated power. All errors in generated power are all underestimates below $5 \%$. The slightly larger errors of the 450 scenario may due to higher than expected efficiency improvements in this scenario defined by the IEA [13].

Table 3: Errors in Predicted Power Generation

\begin{tabular}{|c|c|c|c|c|c|c|}
\hline \multirow{2}{*}{$\mathbf{2 0 1 4}$} & \multicolumn{2}{|c|}{ Current Policies } & \multicolumn{2}{c|}{ New Policies } & \multicolumn{2}{c|}{$\mathbf{4 5 0}$ Scenario } \\
\cline { 2 - 7 } & $\mathbf{2 0 2 0}$ & $\mathbf{2 0 3 0}$ & $\mathbf{2 0 2 0}$ & $\mathbf{2 0 3 0}$ & $\mathbf{2 0 2 0}$ & $\mathbf{2 0 3 0}$ \\
\hline$-1.13 \%$ & $-2.01 \%$ & $-0.99 \%$ & $-1.96 \%$ & $-2.80 \%$ & $-3.46 \%$ & $-2.17 \%$ \\
\hline
\end{tabular}

\subsection{Quantifying Environmental Effects}

The environmental effects of the waste heat were analysed in two ways: the radiative forcing of the waste heat compared to $\mathrm{CO}_{2}$ radiative forcing, and the radiative forcing of the $\mathrm{CO}_{2}$ associated with the theoretical WHR potential (i.e. of the fossil fuels inputs which could be reduced through waste heat recovery).

Assuming significant use of negative emissions technology will not occur over the timescales investigated, all current atmospheric $\mathrm{CO}_{2}$ can be considered permanent. As a result, only the forcing of thermal and $\mathrm{CO}_{2}$ emissions from 2014 (taken as 'the present' due to data availability) onwards were considered.

\subsubsection{Radiative Forcing}

\section{Radiative Forcing of Waste Heat}


Radiative forcing of EL waste heat was calculated using the heat available by cooling the EL streams to ambient temperature. Due to its non-cumulative nature, determination of radiative forcing was straightforward: annual EL values were converted from energy per annum to energy per second, and averaged over the surface of the Earth. Linear interpolation was used to estimate waste heat data between 2014 and 2020, and between 2020 and 2030.

\section{Radiative Forcing of Carbon Dioxide}

As the most emitted greenhouse gas, $\mathrm{CO}_{2}$ absorbs outgoing infrared radiation, and reemits it back towards the Earth's surface, thus trapping heat within the Earth's atmosphere. Quantification of this phenomenon can be expressed through radiative forcing. Radiative forcing of $\mathrm{CO}_{2}$ increases with atmospheric $\mathrm{CO}_{2}$ concentration, and is thus cumulative: $\mathrm{CO}_{2}$ released in one year is still mostly present in subsequent years, and thus affects the subsequent years in addition to the $\mathrm{CO}_{2}$ released in those years. A change in atmospheric $\mathrm{CO}_{2}$ of $1 \mathrm{ppm}$ corresponds to an increase of around 7,762 Mt of $\mathrm{CO}_{2}$ [10]. Therefore, by knowing the net amount of $\mathrm{CO}_{2}$ put into the atmosphere each year, it is possible to calculate the corresponding increase in atmospheric concentration. Total $\mathrm{CO}_{2}$ emissions for years 2014,2020 , and 2030 were given in the WEO for each scenario, and linear interpolation was used to calculate values in between these data points. Zhang et al. assumed a pulse function for future $\mathrm{CO}_{2}$ emissions, with several decay mechanisms (corresponding to absorption out of the atmosphere) with associated time constants [10]. However, such an approach ignores the decay of previous emissions and leads to overly high atmospheric $\mathrm{CO}_{2}$ levels in the short-term. The approach taken in this investigation was to assume that only a certain proportion (termed the "airborne fraction" in literature) reaches the atmosphere.

The airborne fraction depends on anthropogenic land use change, behaviour of carbon sinks (the ocean and land), and natural events such as volcanic activity or El Niño. Prediction of future behaviour of carbon sinks, and in particular the ocean, is hard. However, 
there is a consensus that the airborne fraction will increase with atmospheric $\mathrm{CO}_{2}$, leading to a positive feedback effect. There have been many attempts at quantifying the airborne fraction, for example:

- $\quad$ The IPCC suggests $61.8 \%$ between 1980 and 1999, 48.4\% between 1990 and 1999, and $51.8 \%$ between 2002 and 2011 [7].

- Le Quéré gives a figure of $45 \%$ and an upwards trend of $0.7 \%+/-1.4 \%$ per decade [21].

- Jones and Cox state $40 \%+/-14 \%$, after accounting for the effects of El Niño [22].

The difficulty in accurately measuring global carbon fluxes is evident in the large error ranges of results. However, as stated in [22], "the carbon cycle absorbs approximately half of the emissions", and a figure of $50 \%$ would tend to agree with existing literature. Furthermore, if applied to data until 2040, 2015 atmospheric $\mathrm{CO}_{2}$ matches recorded levels (obtained from [23]) closely, and only the 450 Scenario has an atmospheric concentration below 450 ppm by 2040 , as expected. The increasing trend of the airborne fraction was ignored due to its uncertainty and likely minor effect over 16 years based on literature.

Using emissions data and the airborne fraction, the annual increase in radiative forcing due to total societal $\mathrm{CO}_{2}$ emissions was calculated for each year between 2014 and 2030, using Eq. 3.9 (obtained from [9]):

$$
\Delta \mathrm{F}_{\mathrm{i}}=5.35 \times \ln \left(\frac{\mathrm{c}_{\mathrm{i}}}{\mathrm{c}_{2013}}\right)
$$

where $c_{i}$ refers to atmospheric concentration of $\mathrm{CO}_{2}$ in year $\mathrm{i}$, and $\Delta F_{i}$ refers to the increase in radiative forcing (in $\mathrm{Wm}^{-2}$ ) in year $i$.

\subsection{2 $\mathrm{CO}_{2}$ Associated with Recoverable Waste Heat}

WHR from streams generated by fossil fuel use would allow reduction in primary energy requirements for the same useful output, and thus lead to a reduction in $\mathrm{CO}_{2}$ emissions. The $\mathrm{CO}_{2}$ associated with recoverable waste heat therefore refers to the $\mathrm{CO}_{2}$ that could be avoided by full recovery of the exergetic content of such waste heat. The reduction in fuel use is calculated as follows, illustrated in Fig. 3. 
- For an fuel input energy $X$, there exists a fuel-specific exergy factor s giving the ratio of exergy:LHV. Therefore, the input exergy is $X^{*} s$.

- For an input exergy $X^{\star} s$, an exergy $Y$ of recoverable waste heat will be output.

- Assuming full heat recovery, only a fuel input exergy $\left(X^{*} S-Y\right)$ is required, corresponding to an fuel input energy $\left(\mathrm{X}^{\star} \mathrm{S}-\mathrm{Y}\right) / \mathrm{s}$, a reduction of $\mathrm{Y} / \mathrm{s}$ for the same energy output.

Factors for the ratio of $\mathrm{CO}_{2}$ emissions:LHV were derived from WEO data, and LHV:exergy ratios were taken from [24]. Therefore, the avoided $\mathrm{CO}_{2}$ from full waste heat recovery can be calculated from avoided fuel use.

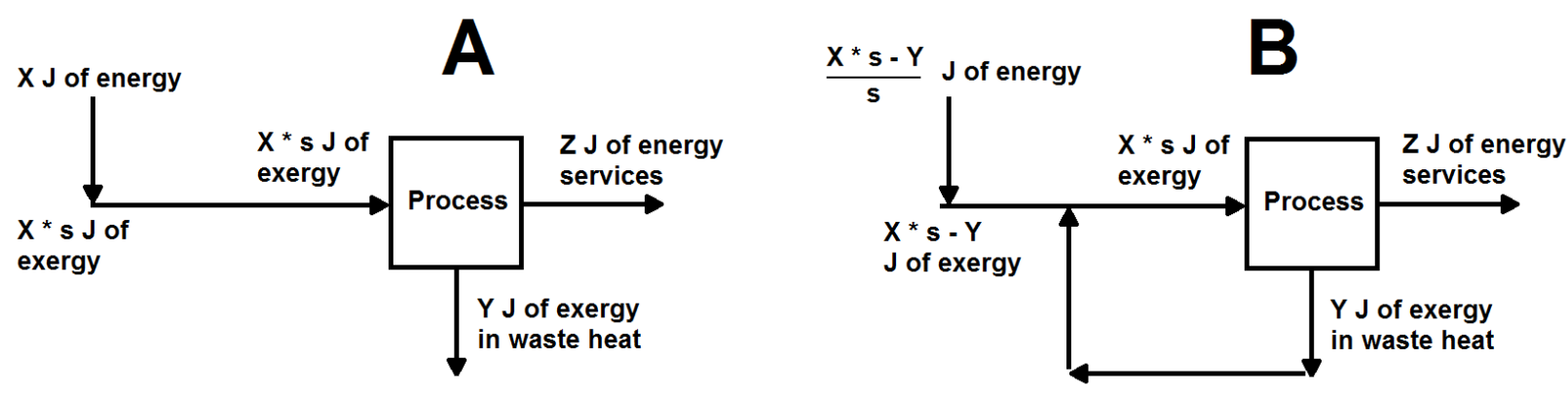

Figure 3: Graphical representation of fuel reduction calculation through full heat recovery. Plots are A: System without waste heat recovery, B: System with waste heat recovery. 


\section{Results and Analysis}

The overall and sectoral waste heat generation for the four scenarios with reference to 2014 and 2030 are presented. The associated environmental impact (i.e. radiative forcing and $\mathrm{CO}_{2}$ emissions) and economic potential are estimated. Sensitivity analysis is included to investigate the impact of several parameters of interest. Throughout this section, the term 'EL' is used to refer to the energetic content of waste heat streams. Any values given as ranges correspond to the range of results obtained depending on year and scenario.

\subsection{Waste Heat Quantification \\ 3.1.1 General Trends}

There are several general trends which can be observed at almost all levels of analysis. Firstly, one of the key factors determining overall waste heat values is total energy use. Expectedly, the Aggressive scenario has the lowest energy use for each given year while the

$\mathrm{CP}$ scenario has the highest, a trend which translates to overall waste heat figures. As a result, absolute waste heat values tend to increase in CP and NP, since energy use continues to increase with no fundamental change in the energy mix. In the 450 scenario, depending on the area of analysis (e.g. specific sectors or sub-sectors), there is either an increase between 2014 and 2030, or a peak in energy use followed by a decrease to near2014 levels by 2030.

Secondly, the proportional contribution of waste heat (e.g. theoretical potential relative to input or relative to EL) among the three WEO scenarios tends to be relatively similar. This may be due in part to conservative projections by the IEA; comparison of the inputs between 2014 and 2030 in the 450 scenario shows relatively little variation in most sectors, as shown in Fig. 4. This notion is corroborated by the findings of Haegel et al., who show that even optimistic IEA projections of solar PV have consistently been underestimated [25]. Other possible reasons are suggested in Section 4.6. Due to its high degree of electrification, the 
Aggressive scenario does display significant variation, typically through lower proportional waste heat production, and a higher proportion of low-temperature waste heat.

Thirdly, the proportion of input energy wasted as heat tends to decrease over time. This is easily explained as current trends are towards a de-carbonised society and higher efficiencies (mainly due to fuel switching, as relatively few processes have had efficiency improvements predicted in this study). Furthermore, comparing scenarios, the stronger the drive towards decarbonisation (and thus away from high-temperature, high-waste heat processes), the bigger the drop in input energy wasted as EL, as would be expected.

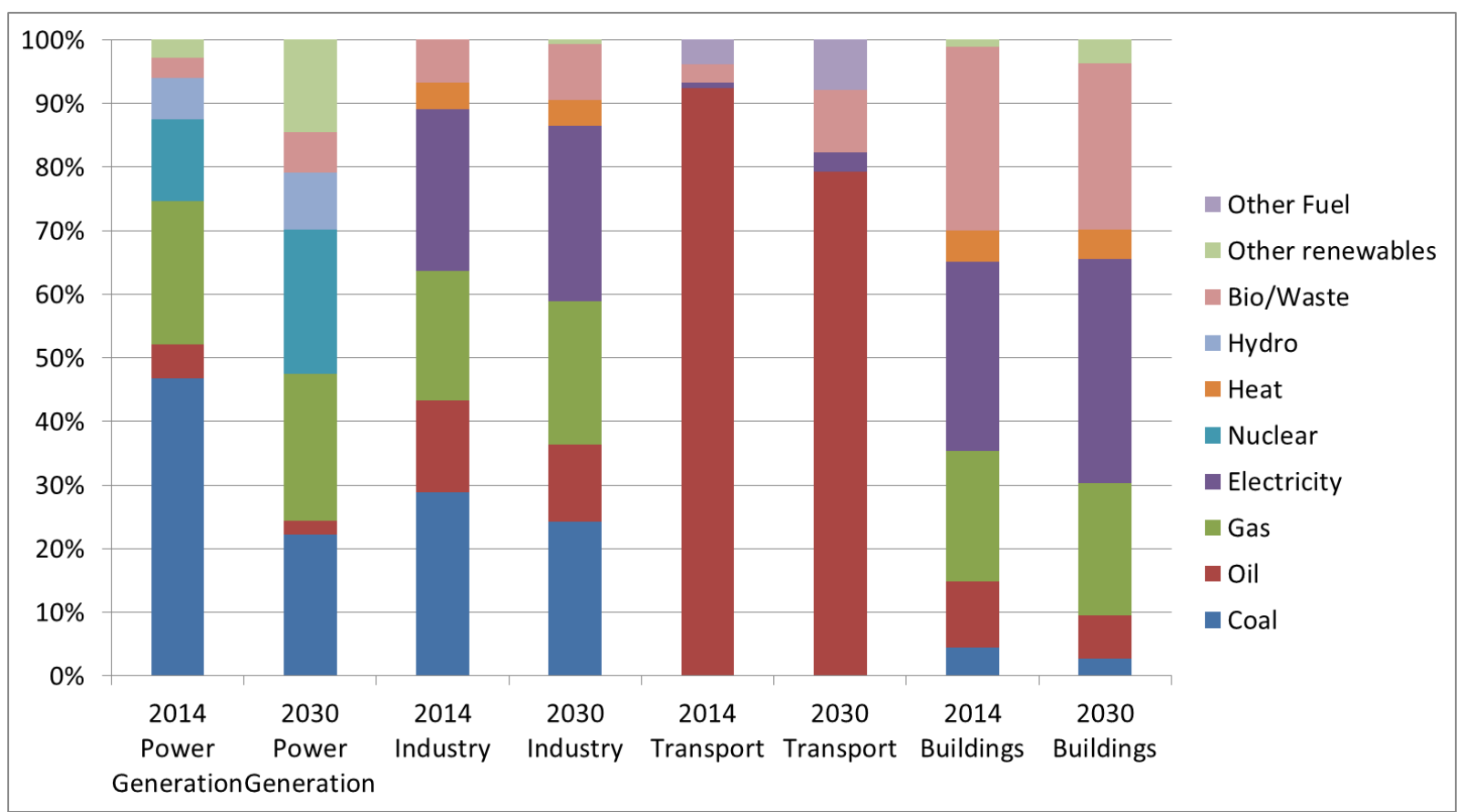

Figure 4: Comparison of sectoral fuel inputs between the year 2014 and the year 2030 according to the 450 scenario.

\subsubsection{Overall Waste Heat}

Overall waste heat figures and temperature distributions are given for each scenario and year in Table 4 and Fig. 5 (note 'Input' refers to overall input to all sectors analysed). Absolute values of waste heat give an indication of the overall magnitude, whereas values relative to input give an indication of inefficiency or wastefulness. The theoretical potential as a fraction of EL gives an indication of the ease of energy recovery from the waste heat 
source. There are several waste heat trends that can be noticed and analysed through the results shown.

In the three main scenarios, $49-53 \%$ of input energy is released as waste heat, while only $11-12 \%$ is thermodynamically recoverable. As can be seen by the temperature distribution graph (Fig. 5), this is due to $64-65 \%$ of waste heat being low-temperature $\left(<100^{\circ} \mathrm{C}\right)$, and only a small proportion of the low-temperature heat contributes to the theoretical potential due to the thermodynamic limits imposed by the Carnot efficiency. The majority of the theoretical potential (63\%) is between $100^{\circ} \mathrm{C}$ and $300^{\circ} \mathrm{C}$, so-called medium-temperature range. The contribution of high-temperature waste heat $\left(>300^{\circ} \mathrm{C}\right)$ to the theoretical potential is almost as high as that of low-temperature, despite there being over 12 times less overall waste heat in the former temperature band than the latter. The implied conclusion of this is that hightemperature waste heat will be far more concentrated and therefore practical to recover.

Results in the Aggressive scenario differ significantly from the main scenarios, with the proportional EL generation and theoretical potential approximately halved, at $23.0 \%$ and $6.2 \%$ respectively. However, the theoretical potential as a function of EL is only slightly different than in other scenarios. This implies that, although proportional EL generation is strongly reduced in the Aggressive scenario, the temperature distribution of the waste heat will be fairly similar. This can be seen in Fig. $5 \mathrm{~A}$, with the most notable difference being an increase in high-temperature waste heat at the expense of medium-temperature. Reasons for this increase are suggested in Section 4.1.

Table 4: Global Waste Heat Simulation Results

\begin{tabular}{|c|c|c|c|c|c|c|}
\hline Year/Scenario & $\begin{array}{c}\text { Input } \\
\text { (PJ) }\end{array}$ & $\begin{array}{c}\text { EL } \\
\text { (PJ) }\end{array}$ & $\begin{array}{c}\text { EL } \\
\text { (\% Input) }\end{array}$ & $\begin{array}{c}\text { Theoretical } \\
\text { Potential } \\
\text { (PJ) }\end{array}$ & $\begin{array}{c}\text { Theoretical } \\
\text { Potential } \\
\text { (\% Input) }\end{array}$ & $\begin{array}{c}\text { Theoretical } \\
\text { Potential } \\
\text { (\% EL) }\end{array}$ \\
\hline $\mathbf{2 0 1 4}$ & 493,000 & 262,000 & $53.0 \%$ & 57,000 & $11.6 \%$ & $21.8 \%$ \\
\hline $\mathbf{2 0 3 0}$ & \multicolumn{7}{|l|}{} & & \\
\hline CP & 625,000 & 322,000 & $51.5 \%$ & 70,300 & $11.2 \%$ & $21.8 \%$ \\
\hline NP & 589,000 & 301,000 & $51.1 \%$ & 66,100 & $11.2 \%$ & $21.9 \%$ \\
\hline 450 & 522,000 & 258,000 & $49.3 \%$ & 58,700 & $11.2 \%$ & $22.8 \%$ \\
\hline Aggressive & 389,000 & 89,700 & $23.0 \%$ & 24,300 & $6.2 \%$ & $27.0 \%$ \\
\hline
\end{tabular}




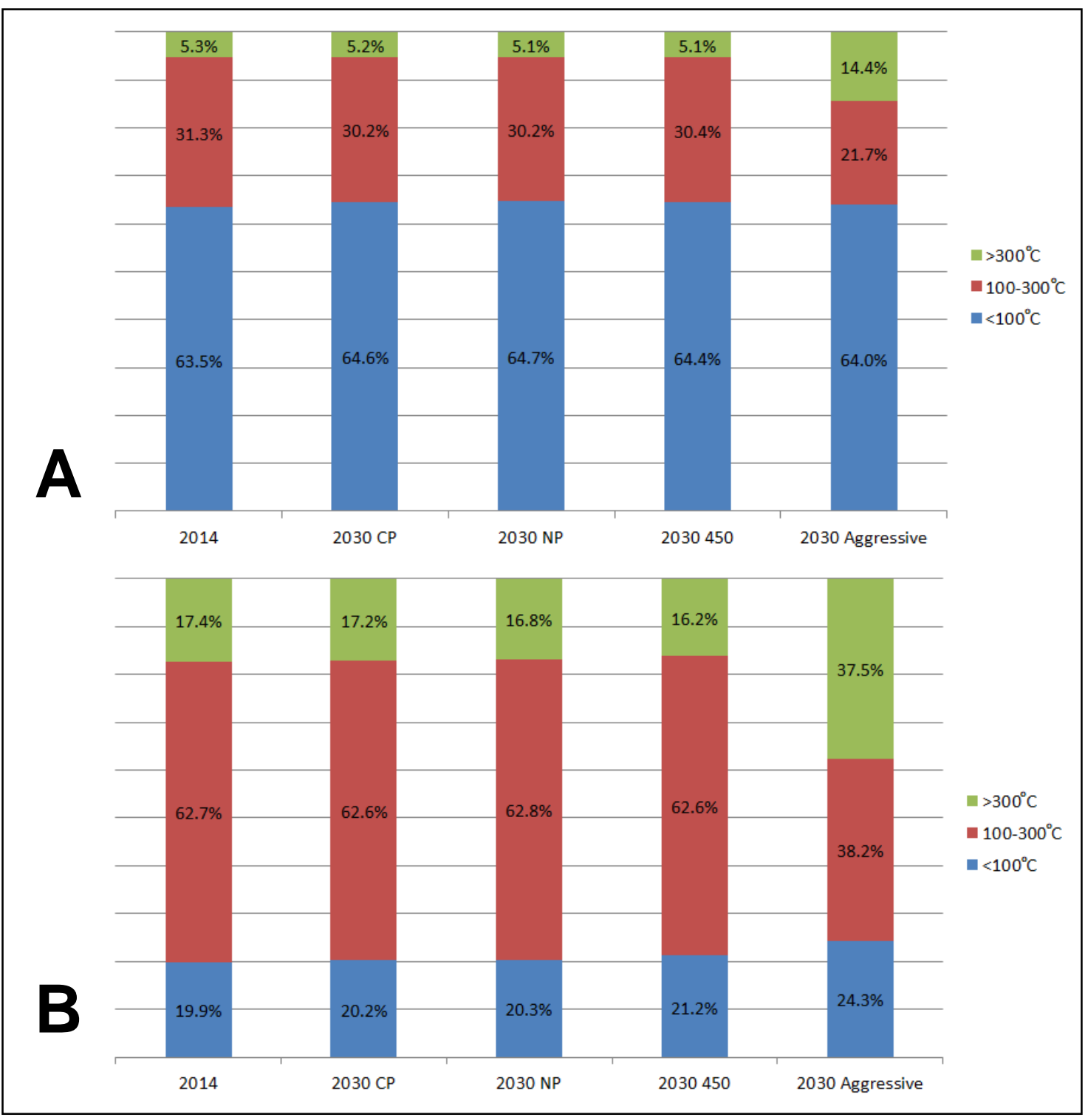

Figure 5: Temperature distributions of waste heat. Plots are A: Distribution of global EL,

B: Distribution of the global theoretical potential.

\subsubsection{Sectoral Waste Heat}

Further insight can be gained from a sectoral analysis. Fig. 6 demonstrates the importance of including the Carnot potential in the analysis of waste heat: the split of overall waste heat between sub-sectors is far different to that of the theoretical potential. 


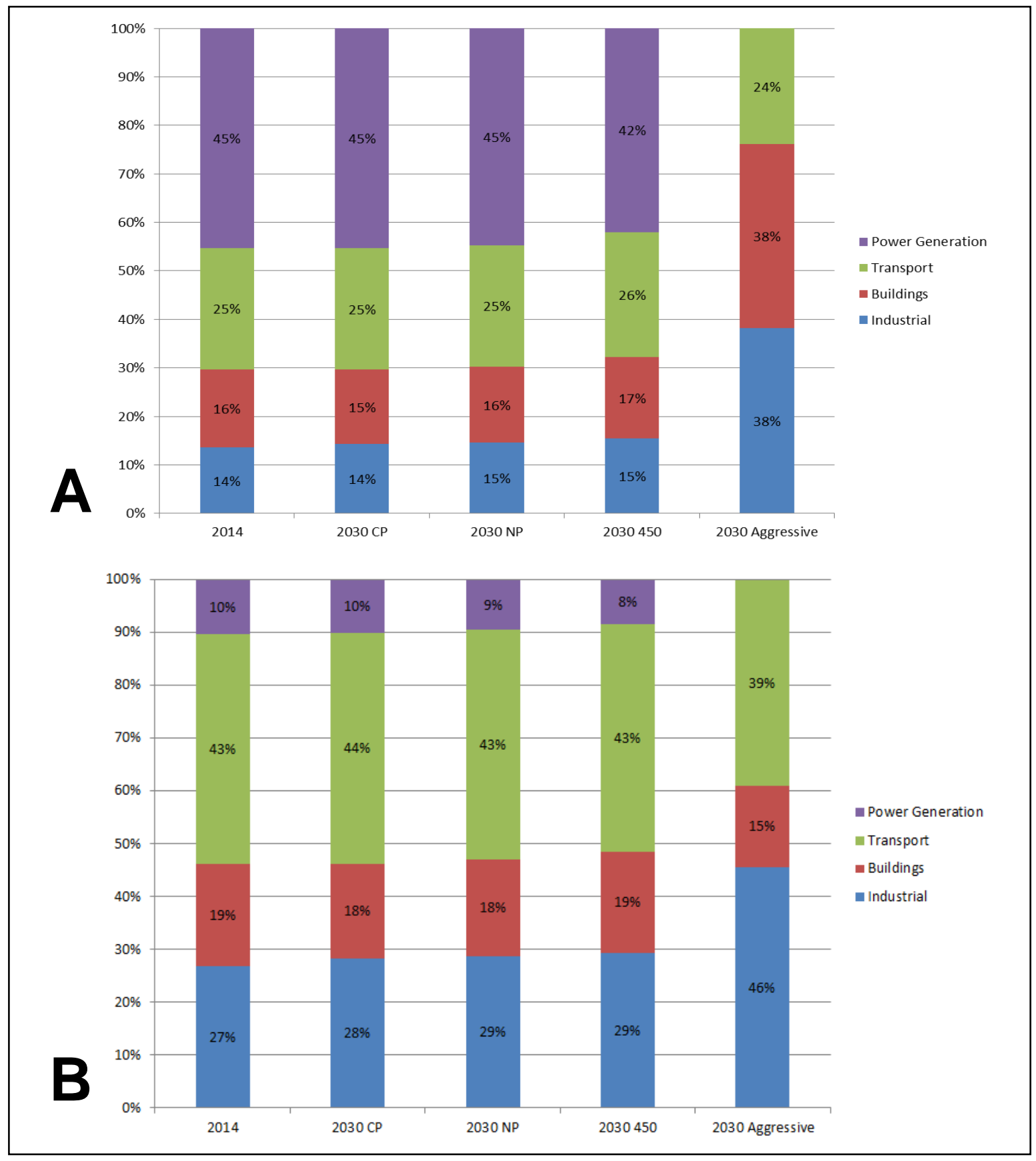

Figure 6: Sectoral distributions of waste heat. Plots are A: Distribution of global EL,

B: Distribution of the global theoretical potential.

\section{Power Generation}


The Power Generation sector dominates global EL in the main scenarios, accounting for $42-45 \%$, but only accounts for $8-10 \%$ of the global theoretical potential. Its high overall waste heat contribution is due to both its high input energy and the thermodynamic limitations of the cycles used in power plants. This leads to $47-55 \%$ of input being released as waste heat. In the Aggressive scenario, however, waste heat is assumed to be eliminated through full conversion to water, wind, and solar power (WWS).

The effects of relatively modest CCS implementation in the 450 scenario (only $7 \%$ of generated power by 2030) can be observed in the theoretical potential relative to EL: the proportion of EL that is recoverable increases is similar to the CP and NP scenarios (see Table 5) despite a particularly pronounced increase in low-temperature EL. This can be attributed to higher-temperature waste heat streams from the CCS process, which account for $24 \%$ of the theoretical potential but only $12 \%$ of sectoral EL. The effects of these CCS streams are discussed in Section 3.4.

Table 5: Power Generation Sector Waste Heat Simulation Results

\begin{tabular}{|c|c|c|c|c|c|c|}
\hline Year/Scenario & $\begin{array}{c}\text { Input } \\
\text { (PJ) }\end{array}$ & $\begin{array}{c}\text { EL } \\
\text { (PJ) }\end{array}$ & $\begin{array}{c}\text { EL } \\
\text { (\% } \\
\text { Input) }\end{array}$ & $\begin{array}{c}\text { Theoretical } \\
\text { Potential } \\
\text { (PJ) }\end{array}$ & $\begin{array}{c}\text { Theoretical } \\
\text { Potential } \\
\text { (\% Input) }\end{array}$ & $\begin{array}{c}\text { Theoretical } \\
\text { Potential } \\
\text { (\% EL) }\end{array}$ \\
\hline $\mathbf{2 0 1 4}$ & 215,000 & 118,000 & $55.0 \%$ & 5,860 & $2.72 \%$ & $4.95 \%$ \\
\hline $\mathbf{2 0 3 0}$ & \multicolumn{7}{|l|}{} \\
\hline CP & 285,000 & 146,000 & $51.3 \%$ & 7,050 & $2.48 \%$ & $4.83 \%$ \\
\hline NP & 263,000 & 135,000 & $51.2 \%$ & 6,230 & $2.37 \%$ & $4.63 \%$ \\
\hline 450 & 228,000 & 107,000 & $47.2 \%$ & 4,930 & $2.16 \%$ & $4.59 \%$ \\
\hline Aggressive & 314,656 & 0 & 0 & 0 & 0 & 0 \\
\hline
\end{tabular}

\section{Industry}

Despite accounting for the lowest proportion of overall waste heat (14-15\%), the Industry sector has the second highest portion of the theoretical potential in the main scenarios (27$29 \%)$. This correctly implies that the waste heat which is available in the Industry sector tends to be at higher temperatures: this sector has both the lowest proportion of lowtemperature waste heat (38-40\%) and the highest proportion of high-temperature waste heat $(20-22 \%)$. As a result, the proportion of EL which is recoverable is the highest of all sectors: around 44\% (see Table 6). 
Table 6: Industry Sector Waste Heat Simulation Results

\begin{tabular}{|c|c|c|c|c|c|c|}
\hline Year/Scenario & $\begin{array}{c}\text { Input } \\
\text { (PJ) }\end{array}$ & $\begin{array}{c}\text { EL } \\
\text { (PJ) }\end{array}$ & $\begin{array}{c}\text { EL } \\
\text { (\% } \\
\text { Input) }\end{array}$ & $\begin{array}{c}\text { Theoretical } \\
\text { Potential } \\
\text { (PJ) }\end{array}$ & $\begin{array}{c}\text { Theoretical } \\
\text { Potential (\% } \\
\text { Input) }\end{array}$ & $\begin{array}{c}\text { Theoretical } \\
\text { Potential } \\
\text { (\% EL) }\end{array}$ \\
\hline $\mathbf{2 0 1 4}$ & 123,000 & 35,500 & $28.7 \%$ & 15,300 & $12.4 \%$ & $43.2 \%$ \\
\hline $\mathbf{2 0 3 0}$ & \multicolumn{7}{|l|}{} \\
\hline CP & 166,000 & 46,100 & $27.8 \%$ & 19,900 & $12.0 \%$ & $43.2 \%$ \\
\hline NP & 158,000 & 44,000 & $27.8 \%$ & 19,000 & $12.0 \%$ & $43.2 \%$ \\
\hline $\mathbf{4 5 0}$ & 143,000 & 39,900 & $27.9 \%$ & 17,300 & $12.1 \%$ & $43.3 \%$ \\
\hline Aggressive & 159,000 & 34,200 & $21.5 \%$ & 11,100 & $7.0 \%$ & $32.3 \%$ \\
\hline
\end{tabular}

\section{Transport}

In the main scenarios, the Transport sector accounts for the second highest quantity of EL (25-26\% of the global amount) and for the largest proportion of global theoretical potential (43-44\%). Efficiencies in this sector are low, principally due to the thermodynamic and practical limitations of the Otto and Diesel Cycles, with $57-59 \%$ of input being released as EL. Similarly to the Power Generation sector, this leads to high quantities of waste heat. Furthermore, output streams in this sector tend to be at higher temperatures, with only $46 \%$ in the low-temperature range. The combination of large quantities of waste heat with this temperature distribution leads to such a large theoretical potential relative to input (see Table 7). Much of this originates from Internal Combustion Engines (ICEs) from the Road subsector, but there are also other significant streams such as those from jet engines in the Aircraft sub-sector.

Table 7: Transport Sector Waste Heat Simulation Results

\begin{tabular}{|c|c|c|c|c|c|c|}
\hline Year/Scenario & $\begin{array}{c}\text { Input } \\
\text { (PJ) }\end{array}$ & $\begin{array}{c}\text { EL } \\
\text { (PJ) }\end{array}$ & $\begin{array}{c}\text { EL } \\
\text { (\% } \\
\text { Input) }\end{array}$ & $\begin{array}{c}\text { Recoverable } \\
\text { (PJ) }\end{array}$ & $\begin{array}{c}\text { Recoverable } \\
\text { (\% Input) }\end{array}$ & $\begin{array}{c}\text { Recoverable } \\
\text { (\% EL) }\end{array}$ \\
\hline $\mathbf{2 0 1 4}$ & 110,000 & 65,300 & $59.4 \%$ & 24,800 & $22.5 \%$ & $37.9 \%$ \\
\hline $\mathbf{2 0 3 0}$ & \multicolumn{7}{|l|}{} \\
\hline CP & 139,000 & 80,300 & $57.9 \%$ & 30,700 & $22.1 \%$ & $38.2 \%$ \\
\hline NP & 131,000 & 75,500 & $57.8 \%$ & 28,700 & $22.0 \%$ & $38.0 \%$ \\
\hline $\mathbf{4 5 0}$ & 116,000 & 66,500 & $57.4 \%$ & 25,200 & $21.8 \%$ & $37.9 \%$ \\
\hline Aggressive & 63,000 & 21,500 & $34.1 \%$ & 9,500 & $15.0 \%$ & $44.1 \%$ \\
\hline
\end{tabular}

\section{Buildings}


In the main scenarios, the Buildings sector offers EL comparable to that of the similarlysized Industry sector (15-17\% of global EL). However, the consequence of their different temperature distributions soon becomes apparent: the Buildings sector accounts for only 19$20 \%$ of the global theoretical potential, around two thirds the contribution of Industry. This is principally due to its total lack of high-grade waste heat according to the process data used. The majority of medium-grade waste heat is due to fossil-fuel and biomass burners, whereas low-temperature waste heat tends to come from electrical space and water heating, as well as appliances and lighting.

Table 8: Buildings Sector Waste Heat Simulation Results

\begin{tabular}{|c|c|c|c|c|c|c|}
\hline Year/Scenario & $\begin{array}{c}\text { Input } \\
\text { (PJ) }\end{array}$ & $\begin{array}{c}\text { EL } \\
\text { (PJ) }\end{array}$ & $\begin{array}{c}\text { EL } \\
\text { (\% } \\
\text { Input) }\end{array}$ & $\begin{array}{c}\text { Recoverable } \\
\text { (PJ) }\end{array}$ & $\begin{array}{c}\text { Recoverable } \\
\text { (\% Input) }\end{array}$ & $\begin{array}{c}\text { Recoverable } \\
\text { (\% EL) }\end{array}$ \\
\hline $\mathbf{2 0 1 4}$ & 126,000 & 42,300 & $33.5 \%$ & 11,100 & $8.76 \%$ & $26.2 \%$ \\
\hline $\mathbf{2 0 3 0}$ & \multicolumn{7}{|l|}{} \\
\hline CP & 155,000 & 49,500 & $32.0 \%$ & 12,600 & $8.13 \%$ & $25.4 \%$ \\
\hline NP & 147,000 & 47,100 & $32.0 \%$ & 12,100 & $8.20 \%$ & $25.6 \%$ \\
\hline $\mathbf{4 5 0}$ & 137,000 & 43,600 & $31.9 \%$ & 11,200 & $8.22 \%$ & $25.8 \%$ \\
\hline Aggressive & 144,000 & 34,100 & $23.6 \%$ & 3,700 & $2.59 \%$ & $11.0 \%$ \\
\hline
\end{tabular}

\subsection{Environmental Effects}

The environmental effects analysed in this report are the radiative forcing of the waste heat, and of the avoidable $\mathrm{CO}_{2}$ emissions associated with the theoretical potential in WHR. Fig. 7 shows the evolution of both $\mathrm{CO}_{2}$ radiative forcing and $\mathrm{EL}$ radiative forcing with and without full heat recovery (i.e. all theoretical potential recovered), as well as the forcing of the $\mathrm{CO}_{2}$ avoided by full WHR. These results are from the NP scenario, but all future scenarios exhibit similar trends and ratios of $\mathrm{CO}_{2}$ forcing to $\mathrm{EL}$ forcing. They can therefore be considered representative of all future scenarios. 


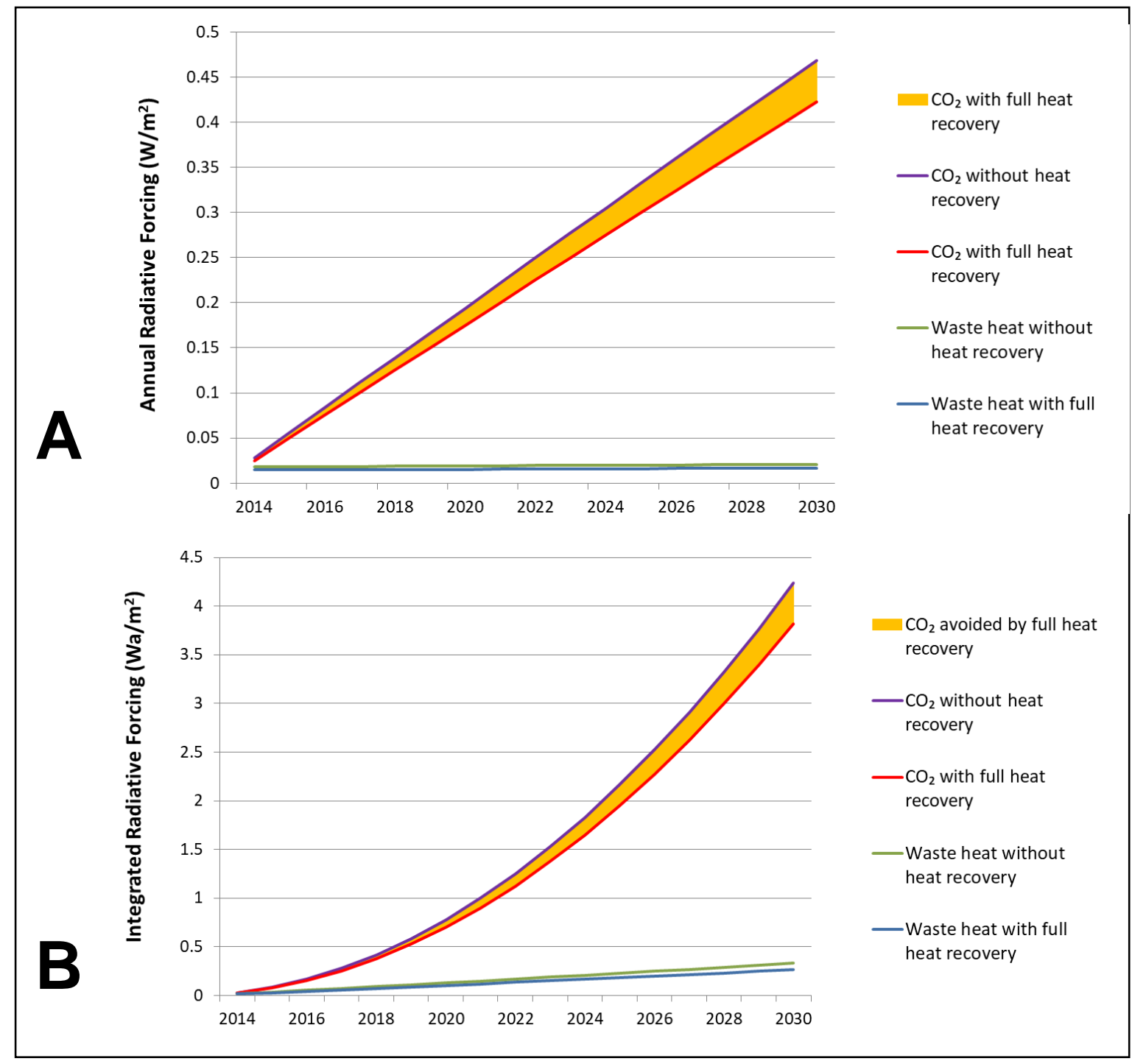

Figure 7: Comparison of radiative forcing due to waste heat, total societal $\mathrm{CO}_{2}$, and avoidable $\mathrm{CO}_{2}$ in the NP scenario, with no WHR and with full WHR. Plots are A: Annual radiative forcing over time, $\mathrm{B}$ : Integrated radiative forcing over time. The unit $\mathrm{Wa}$ is the energy produced at one Watt over one year.

\subsubsection{EL Forcing}

In the main scenarios, the forcing of EL was found to vary between around 0.018 and $0.022 \mathrm{Wm}^{-2}$. This represents $70-85 \%$ of the annual radiative forcing increase due to $\mathrm{CO}_{2}$ emissions. However, this figure is misleading without considering the cumulative effect of $\mathrm{CO}_{2}$ forcing over time: current overall $\mathrm{CO}_{2}$ forcing (i.e. due to total $\mathrm{CO}_{2}$ concentration in the atmosphere pre-2014) is of around $1.82 \mathrm{Wm}^{-2}$ [7], around 100 times larger than that of waste 
heat. In plot $\mathrm{A}$, one can clearly see that $\mathrm{CO}_{2}$ radiative forcing rapidly increases relative to that of waste heat. At the end of the investigation period in the NP scenario, $\mathrm{CO}_{2}$ radiative forcing is 22 times larger, increasing almost linearly with time while EL forcing stays essentially constant.

The overall effect on the planet can be estimated by integrating the total annual radiative forcing over time, accounting for the additional heat that's discounted from the Earth's outgoing heat flux, thus giving the total heat 'retained' within the atmosphere. This method is a simplified estimation to account for the disturbance in the Earth's complex heat balance, serving as a useful measure for comparison between scenarios over the relatively short timescales investigated. For plot $\mathrm{B}$, by the end of the period of investigation, the overall effect of $\mathrm{CO}_{2}$ forcing is found to be 13 times greater than that of waste heat forcing, with this ratio increasing year upon year.

\subsubsection{Extra $\mathrm{CO}_{2}$ and WHR}

It can be argued that the full effects of the waste heat include those of the extra $\mathrm{CO}_{2}$. The term 'extra $\mathrm{CO}_{2}$ ' has been explained in Section 2.4, and refers to the $\mathrm{CO}_{2}$ emissions that could be avoided through full recovery of the theoretical potential. Table 9 gives the potential $\mathrm{CO}_{2}$ savings.

Table 9: $\mathrm{CO}_{2}$ Avoided Through Full Recovery of the Theoretical Potential

\begin{tabular}{|c|c|c|c|c|c|}
\hline Year & \multirow{2}{*}{2014} & \multicolumn{4}{|c|}{$\mathbf{2 0 3 0}$} \\
\cline { 4 - 6 } Scenario & & CP & NP & $\mathbf{4 5 0}$ & Aggressive \\
\hline Avoidable $\mathbf{C O}_{2}$ (Mt) & 3,200 & 3,860 & 3,540 & 2,650 & 1,020 \\
\hline $\begin{array}{c}\text { Avoidable } \mathbf{C O}_{2} \\
\text { (\% total emissions) }\end{array}$ & $9.9 \%$ & $10.0 \%$ & $10.3 \%$ & $10.5 \%$ & $19.2 \%$ \\
\hline
\end{tabular}

In all cases, the theoretical potential accounts for around $22-27 \%$ of total EL waste heat, with the associated $\mathrm{CO}_{2}$ accounting for $10-19 \%$ of annual $\mathrm{CO}_{2}$ emissions. It should be noted that the Aggressive scenario's much larger proportion of avoidable $\mathrm{CO}_{2}$ by 2030 is due to the fully renewable Power Generation sector: fossil fuel-based generation leads to low recoverable energy and thus low avoidable $\mathrm{CO}_{2}$. 
In the short term such significant decreases in EL through WHR lead to almost equally significant decreases in $\mathrm{CO}_{2}$ radiative forcing in absolute terms. However, in the long-term the decrease in EL forcing remains at around $20-25 \%$ while the associated decrease in $\mathrm{CO}_{2}$ forcing gets amplified over time. Over 16 years, the overall reduction in radiative forcing is calculated as $0.32-0.47 \mathrm{Wa} / \mathrm{m}^{2}$, corresponding to $10-12 \%$ of the total radiative forcing over that period. However, around $85 \%$ of this is due to the reduction in $\mathrm{CO}_{2}$. Therefore, the major radiative forcing decrease through full waste heat recovery comes through a reduction in $\mathrm{CO}_{2}$ emissions.

\subsection{Economic Potential and Savings}

This investigation has found that waste heat represents a large proportion of energy losses, and will likely continue to do so regardless of the future emissions path followed. However, it is clear that in reality the full theoretical potential is unlikely to be recovered, with economics expected to be a key driver. As a result, identification of prime areas for economic WHR is important to induce progress, with a view that increasingly common WHR may in turn lead to cost reductions that increase recovery opportunities.

As mentioned in Section 1, the economic potential of WHR refers to the waste heat which is economically favourable to recover. It is a subset of a technical potential which represents the quantity of waste heat that can be practically recovered. The technical potential is typically found through matching of heat sources with WHR technologies and sometimes also with heat sinks, therefore determining the technical potential based on both efficiency of recovery and the matching of supply with demand. Due to the wide-ranging scope of this analysis and limited resources available to this study, determination of a meaningful technical potential was deemed unfeasible. Without relying on a reliable estimate of the technical potential, the theoretical WHR potential of waste heat above $150{ }^{\circ} \mathrm{C}$ was used to approximate the economic potential. This is in accordance to the EPA's 1984 investigation into Industrial Waste Heat (IWH) in the U.S, where $150^{\circ} \mathrm{C}$ was considered the "minimum 
economically feasible recovery temperature" [26]. Shown in Table 10, results indicate a considerable economic potential in all years and scenarios. Trends mirror those of global EL: absolute quantities dependent on overall energy use, with small proportional variations between scenarios.

It should be noted that the economic potentials calculated as such represent upper bounds, rather than precise estimates.

Table 10: Global Economic Potential Results

\begin{tabular}{|c|c|c|c|c|}
\hline Year/Scenario & $\begin{array}{c}\text { Economic } \\
\text { Potential } \\
\text { (PJ) }\end{array}$ & $\begin{array}{c}\text { Economic } \\
\text { Potential } \\
\text { (\% Input) }\end{array}$ & $\begin{array}{c}\text { Economic } \\
\text { Potential } \\
\text { (\% EL) }\end{array}$ & $\begin{array}{c}\text { Economic Potential } \\
\text { (\% Theoretical } \\
\text { Potential) }\end{array}$ \\
\hline $\mathbf{2 0 1 4}$ & 42,100 & $8.5 \%$ & $16.1 \%$ & $73.9 \%$ \\
\hline $\mathbf{2 0 3 0}$ & \multicolumn{4}{|l}{} \\
\hline CP & 51,100 & $8.2 \%$ & $15.9 \%$ & $72.7 \%$ \\
\hline NP & 48,600 & $8.2 \%$ & $16.1 \%$ & $73.5 \%$ \\
\hline $\mathbf{4 5 0}$ & 44,000 & $8.4 \%$ & $17.1 \%$ & $75.0 \%$ \\
\hline Aggressive & 21,200 & $5.5 \%$ & $23.7 \%$ & $87.5 \%$ \\
\hline
\end{tabular}

In addition to the economic savings from reduced fuel use through WHR, there is also the potential for significant savings through avoidance of carbon taxes. As stated in the WEO, current carbon taxes vary significantly between no tax and $\$ 130 /$ tonne of $\mathrm{CO}_{2}$ emitted, and many figures given only apply to certain sub-sectors. A conservative estimate of $\$ 20 /$ tonne (similar to the figure investigated in the UK by Grover et al., which was found to have minor effects on consumers [27]), gives an annual potential savings of $\$ 20 \mathrm{bn}-\$ 77 \mathrm{bn}$ through reduced $\mathrm{CO}_{2}$ emissions.

\subsection{Key Shifts in Main Scenarios}

The results presented in this study indicate that a scenario leading to an increase in global mean temperatures of under $2^{\circ} \mathrm{C}$ (i.e. the 450 scenario) does not comprise dramatic changes in the energy system. Given the technological and market advances, the actual future evolvement of the energy system could be far more significant. In this section, three distinct technological shifts with large effects on the waste heat landscape have been 
identified for the main scenarios: transitioning to renewable power generation, wide-scale implementation of CCS, and switching from ICEs to EVs.

\subsubsection{Renewable (Solar/Wind/Tidal and Hydroelectric) Power Generation}

The Power Generation sector is predicted to have the largest drop in EL, principally due to the emergence of renewables (taken here to mean solar/wind/tidal and hydroelectric) as a strong competitor to fossil-fuel power generation. Under the assumption of no EL losses for renewables, each PJ of electricity generated by renewables rather than fossil fuels leads to a decrease in EL of between 1.09 and 1.71 PJ depending on the type of fossil fuel displaced and year. Furthermore, for every $10 \%$ increase in the proportion of total power generated by renewables at the expense of non-CCS fossil fuels (in proportion to their use), there would be a decrease in sectoral EL of $12-13 \%$, a decrease in global EL of $5 \%$, and an absolute increase in global efficiency of around $2 \%$. In the case of $100 \%$ renewable power generation (as in the Aggressive scenario), total waste heat in the 450 scenario decreases from around 2.9 times to 1.5 times that of the Aggressive scenario. This further demonstrates that the key change in the Aggressive scenario is in the Power Generation sector.

\subsubsection{CCS}

It was decided to model all future CCS as post-combustion due to its retrofitting ability (especially important in a scenario where fossil fuel-fired plants and particularly coal-fired are being phased out), relative simplicity, and maturity. The process was assumed to use MonoEthanolAmine (MEA) as the $\mathrm{CO}_{2}$ solvent, due to its maturity and availability of data. The sources of waste heat considered were from the reboiler used for solvent regeneration, cooling of the captured $\mathrm{CO}_{2}$ before compression, and the compression of the liberated $\mathrm{CO}_{2}$. This study estimated that $90 \%$ of $\mathrm{CO}_{2}$ emissions are avoided and overall efficiency of the concomitant power plant is reduced by around $30 \%$ and $20 \%$ for coal- and gas-fired power stations respectively. Efficiency factors were derived using the approach of House et al., with further process assumptions given in Appendix A-5 [28]. Additionally, EL increases by approximately $32 \%$ and $17 \%$, for every unit of electricity produced relative to non-CCS coal 
and gas generation respectively. Out of the EL, around $8-9 \%$ is thermodynamically recoverable, a significantly higher proportion than that for normal thermal power generation (around $5 \%$ ), due to higher-temperature waste heat streams. There is therefore a two-sided environmental effect: a decrease in $\mathrm{CO}_{2}$ radiative forcing at the expense of an increase in waste heat radiative forcing.

Using the 450 scenario data, results were calculated assuming a linear transition from no CCS in 2014 to $100 \%$ of coal- and gas-generated power incorporating CCS in 2030. These were compared to results assuming no CCS implementation in any year, for the same total power generation. Assuming no WHR, the assumed implementation of CCS led to a reduction in overall $\mathrm{CO}_{2}$ forcing over 21 times more significant than the corresponding increase in EL forcing between 2014 and 2030. This indicates that the environmental effects of $\mathrm{CO}_{2}$ avoidance through CCS far outweigh those of the associated increase in EL.

\subsubsection{EVs}

ICEs have been shown to contribute significantly to global waste heat production. However, these engines will almost exclusively tend to be mobile, making WHR challenging. In addition, efficiency of the majority of these engines is thermodynamically limited to around $45 \%$ and $55 \%$ by the Otto and Diesel cycles respectively. As a result, switching from ICEs to EVs would appear to be the most feasible way of reducing this source of waste heat. New socket-to-wheel balance factors were derived for EVs, given in Appendix A-1, assuming EL originated from cooling of $\mathrm{I}^{2} \mathrm{R}$ and friction losses in the motor.

Table 11 summarises some of the effects on waste heat for every $10 \%$ increase in the proportion of 'energy services' in the Road sub-sector delivered by EVs as replacement of ICEs. The effects of increased electricity generation must be included in this sensitivity analysis, and therefore two cases are given: one where the increase in electricity generation is divided proportionally between all fuels, and one where it is provided entirely by solar/wind/tidal and hydroelectric (i.e. those with no EL). These results depend on year and scenario, and are therefore given as a range when appropriate. 
Table 11: Effects of $10 \%$ Increase in EV Market Share

\begin{tabular}{|c|c|c|c|}
\hline $\begin{array}{c}\text { Source of electricity } \\
\text { generation increase }\end{array}$ & $\begin{array}{c}\text { Proportional } \\
\text { decrease in } \\
\text { global EL }\end{array}$ & $\begin{array}{c}\text { Decrease in } \\
\text { global theoretical } \\
\text { potential (\% } \\
\text { global EL) }\end{array}$ & $\begin{array}{c}\text { Increase in } \\
\text { global energy } \\
\text { efficiency }\end{array}$ \\
\hline Existing Fuel Mix & $0.8-1.1 \%$ & $0.6-0.7 \%$ & $0.2 \%$ \\
\hline Solar/Wind/Tidal/Hydroelectric & $1.9-2.0 \%$ & $0.7 \%$ & $0.4 \%$ \\
\hline
\end{tabular}

The fuel mix of the Power Generation sector plays a very large part in determining the extent of global EL reduction and increase in global energy efficiency, but not of the decrease in global theoretical potential (which is relatively insensitive to the fuel mix due to the low theoretical potential of both EVs and power generation).

Another alternative to ICEs are Fuel Cell Electric Vehicles (FCEVs) running on hydrogen, particularly in a hydrogen economy-based future. While the energy requirements for hydrogen generation are high, it is considered to serve as a useful storage medium for intermittent renewable electricity, offering flexibility to the grid [29]. In addition, such vehicles may complement EVs, often considered more suitable for short-distance travel, by providing sufficient energy storage for long-distance road travel. The effect of mixed penetration of FCEVs and EVs powered by renewable electricity (used to generate hydrogen in electrolysers for the former) was therefore also investigated. FCEV balance factors are given in Appendix A-1, and the effect of $70 \%$ efficient atmospheric electrolysers used to generate hydrogen for use in the FCEV [30]. Across all years and main scenarios, a 10\% increase in market share was found to lead to a proportional decrease in global EL of $1.7 \%$ and an absolute increase in global energy efficiency of $0.3 \%$. Effects were therefore in between those of EVs powered by renewables, and those of EVs powered by the existing fuel mix. Findings for EVs and renewables in the Power Generation sector are displayed in Fig. 8. 


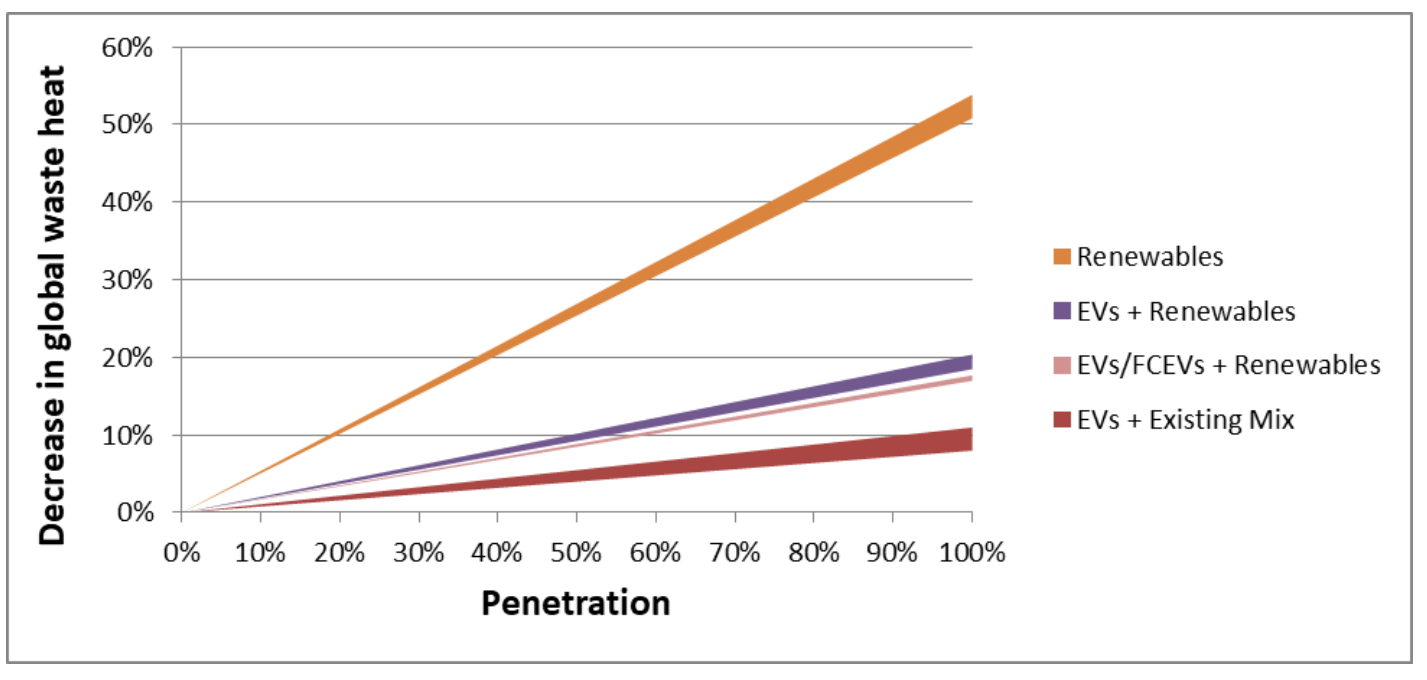

Figure 8: Decrease in global waste heat emissions with increasing penetration of: renewable (solar/wind/tidal/hydroelectric) electricity, electric vehicles (EVs) powered by electricity generated using the existing fuel mix, EVs powered by renewable electricity, and equal proportions of EVs and Fuel Cell EVs powered by renewable electricity. Results are presented as a range for the years 2014 and 2030 according to the three main scenarios. 


\section{Discussion}

\subsection{Overall Waste Heat Results}

In the main scenarios, the quantity of waste heat was found to be significant, accounting for $49.3-53.0 \%$ of global input energy. This is accompanied by a global theoretical WHR potential of $11-12 \%$, and an economic potential of $8-9 \%$. Surprisingly, results showed comparatively small variations in waste heat production (relative to input) over time and between scenarios. This similarity indicates that the most effective way of limiting absolute waste heat emissions is through an overall reduction in energy use rather than realistic fuel switching. Between $63 \%$ and $65 \%$ of waste heat was found to be at low temperatures $\left(<100^{\circ} \mathrm{C}\right)$, with this proportion increasing slightly over time at the expense of mainly mediumtemperature $\left(100-300^{\circ} \mathrm{C}\right)$ waste heat. However, the analysis suggests a distinctively important need for effective medium-temperature WHR, with $63 \%$ of the theoretical potential being in this temperature band. Moreover, the usefulness of low-temperature waste heat is put into question; despite its majority share of overall waste heat, it only contributes towards $20-21 \%$ of the theoretical potential, similar to less abundant high-temperature $\left(>300^{\circ} \mathrm{C}\right)$ waste heat. This implies that efforts in developing WHR technology would be better directed at the latter. However, low-temperature waste heat may still be utilised through better heat integration, for use in low-grade heating applications such as space heating in the Buildings sector. This may be especially practical in the Power Generation sector, which accounts for around $60 \%$ of low-temperature waste heat, and comprises a relatively small number of large waste heat sources.

While the Aggressive scenario may be considered unrealistic in such short timescales, its findings could be considered representative of a more distant, low-carbon society. Even in this scenario, waste heat is found to account for around a quarter of input energy, with a theoretical potential of around $6 \%$. The difference in results between the Aggressive scenario and main scenarios is primarily down to the complete substitution of fossil fuels for water, wind, and solar power (WWS) in the Power Generation sector. This leads to large 
efficiency improvements in both Power Generation, as well as the end-use processes that have been electrified. As a result, waste heat production amounts to under a third of that of the CP scenario, for the same total Energy Services. Although the Aggressive scenario appears similarly skewed towards low-temperature waste heat, the underlying causes are different. Rather than being due to large quantities of very low-temperature heat from the Power Generation sector, it is instead due to the lower temperatures involved in electrified end-use processes. While the temperature distribution of the theoretical potential is relatively similar to that of the main scenarios, there is an increase in the proportion of hightemperature waste heat. This can be explained by the lack of electrification in several parts of the Transport sector, such as aviation. As a result, high-temperature waste heat generation does not decrease as quickly as medium- and low-temperature waste heat in this scenario. Similarly to the other main scenarios, the low theoretical potential of lowtemperature waste heat, despite its majority in terms of EL generation, appears to support the argument that efforts towards high-temperature and medium-temperature WHR will still prove most important in a decarbonised world, where much of the low-temperature waste heat has been eliminated by a switch to renewables-derived electricity.

\subsection{Sectoral Waste Heat}

The Power Generation sector sees the largest drop in EL as a function of input between 2014 and 2030 in all scenarios. In the CP and NP scenarios, due to switching from coal- to gas-fired power plants with improved efficiencies, whereas the significantly lower proportional EL losses in the 450 and Aggressive scenarios can be explained by aggressive market penetration of renewables with no assumed EL.

The Industry sector's waste heat generation relative to input is found to be the lowest of all sectors, which could be explained by the economically competitive nature of industry driving efficiency improvements, as well as economies of scale favouring WHR. Such competition, in addition to the high-temperature streams which characterise the sector, may explain why the majority of existing waste heat analyses have focussed on IWH. 
In the Transport sector, EL as a proportion of input offers some insight as to predicted trends in the main scenarios. EL losses relative to input decrease by up to $2 \%$ by 2030 . Around $1 \%$ of this decrease can be explained through the estimated improvement in average efficiency of ICEs, and the rest is attributable to adoption of Electric Vehicles (EVs). The theoretical potential is therefore predicted to decrease in coming years, but at a fairly low rate due to the gradual projected uptake of EVs, and slow improvements in average efficiency of the large global fleet of ICEs. As a result, the Transport sector is predicted to still be the largest source of recoverable waste heat in 2030 in the main scenarios. In the Aggressive scenario, EV penetration is assumed to be much higher, leading to significant decreases in EL values. However, it has been assumed (as in Jacobson and Delucchi's work $[23,24])$, that the Aircraft sub-sector is not electrified by 2030 . As this sub-sector provides the highest-temperature waste heat, the theoretical potential of the sector relative to input does not decrease as sharply as total waste heat generation.

The Buildings sector offers the most distinct trend in temperature distribution: there is a clear shift towards lower-temperature waste heat, due to a pronounced change from fossil fuels towards renewables and electricity. The increases in the proportion of low-temperature waste heat are larger in the CP and NP scenarios than the 450 scenario. This could be due to the fact that CP and NP experience the largest increases in energy use, therefore proportionally electricity increases are more pronounced. Relative to other sectors, the Aggressive scenario's results are fairly similar to those of the main scenarios. This is due to the Buildings sector currently being more electrified than the others, and so there is a less marked change in fuel mix relative to the main scenarios. As a result of this, waste heat generation in the Buildings sector is not reduced as noticeably as in other sectors. This leads to the proportion of overall EL generated by this sector appearing to increase significantly, from $15-17 \%$ to $44 \%$ (see Fig. 6). Even so, the effects of widespread electrification can be seen in the low theoretical potential. 


\subsection{Hotspots}

While the overall economic potential (see Section 3.3) is useful, it does not give specific information about which sectors and sub-sectors to target preferentially, for WHR, for which hotspots need to be identified. Hotspots can be defined in several ways, and two types will be analysed: sectors and sub-sectors with the largest economic potential, and those with the highest economic potential relative to input. The former represents the largest 'markets' for WHR and thus the greatest financial prospects, while the latter represent the most 'concentrated' areas for WHR, with the biggest gains relative to input.

\subsubsection{Sectors}

Since the four sectors have similar inputs, ranking them in order of absolute economic potential and relative to input give the same result (see Table 12). For the main scenarios:

1. Transport, with between 20 and 24 EJ depending on year and scenario, corresponding to $17-18 \%$ of input energy.

2. Industry, with between 13 and 17 EJ, corresponding to $10-11 \%$ of input energy.

3. Buildings, with between 9 and 10 EJ, corresponding to $7-8 \%$ of input energy

4. Power Generation, with up to 460 PJ, corresponding to only $0.3 \%$ of input energy.

Table 12: Sectoral Economic Potential Results

\begin{tabular}{|c|c|c|c|c|c|c|c|c|}
\hline \multirow{2}{*}{ Year/Scenario } & \multicolumn{2}{|c|}{$\begin{array}{c}\text { Power } \\
\text { Generation }\end{array}$} & \multicolumn{2}{|c|}{ Industry } & \multicolumn{2}{|c|}{ Transport } & \multicolumn{2}{|c|}{ Buildings } \\
\hline & $\begin{array}{l}\text { Total } \\
\text { (PJ) }\end{array}$ & $\begin{array}{c}\% \\
\text { Input }\end{array}$ & $\begin{array}{l}\text { Total } \\
\text { (PJ) }\end{array}$ & $\begin{array}{c}\% \\
\text { Input }\end{array}$ & $\begin{array}{l}\text { Total } \\
\text { (PJ) }\end{array}$ & $\begin{array}{c}\% \\
\text { Input }\end{array}$ & $\begin{array}{l}\text { Total } \\
\text { (PJ) }\end{array}$ & $\begin{array}{c}\% \\
\text { Input }\end{array}$ \\
\hline 2014 & 0 & $0 \%$ & 13,000 & $10.6 \%$ & 19,800 & $18.0 \%$ & 9,270 & $7.3 \%$ \\
\hline \multicolumn{9}{|l|}{2030} \\
\hline CP & 0 & $0 \%$ & 16,900 & $10.2 \%$ & 24,100 & $17.3 \%$ & 10,400 & $6.7 \%$ \\
\hline NP & 0 & $0 \%$ & 16,100 & $10.2 \%$ & 22,400 & $17.2 \%$ & 10,000 & $6.8 \%$ \\
\hline 450 & 460 & $0.2 \%$ & 14,600 & $10.2 \%$ & 19,600 & $16.9 \%$ & 9,320 & $6.8 \%$ \\
\hline
\end{tabular}

\subsubsection{Sub-Sectors}

Given both interpretations of hotspots, the 'top' five sub-sectors were identified for the main scenarios, and can be seen in Table 13. While these results are more useful in terms of targeted WHR, the larger degree of disaggregation means that they also tend to be less accurate. 
Table 13: Sub-sectoral Economic Potential Hotspots

\begin{tabular}{|ll|ll|}
\hline \multicolumn{2}{|l|}{ Economic Potential (EJ) } & \multicolumn{2}{|l|}{ Economic Potential (\% Input) } \\
\hline 1. & Road: $13-17$ & 1. & Aircraft: $35 \%$ \\
\hline 2. & Residential: $7-8$ & 2. & Pipeline Transport: $17-18 \%$ \\
\hline 3. & Aircraft: $4-5$ & 3. & Non-Metallic Minerals: $16-17 \%$ \\
\hline 4. & Non-Metallic Minerals: 3 & 4. & Shipping: $15-20 \%$ \\
\hline 5. & Iron and Steel: $2-3$ & 5. & Road: $15 \%$ \\
\hline
\end{tabular}

In these scenarios and years, the five sub-sectors with the largest overall economic potentials are very similar. These account for around $70 \%$ of the global economic potential. However, they are clearly dominated by the Road sector, with a contribution around twice as high as any other sub-sector and corresponding to slightly under a third of the global economic potential.

The five sub-sectors with the largest economic potentials relative to input are also very similar throughout scenarios. As expected, all are from the Industry and Transport sectors, with the lower energy intensity Buildings sector far behind, as evidenced by the Residential sub-sector being second in terms of absolute waste heat but outside the top five in terms of proportion of input. The Aircraft sub-sector dominates this list due to the extremely high exhaust temperatures of jet engines. However, the practical limitations of aircraft WHR are substantial.

\subsubsection{Environmental Effects}

Through the implementation of carbon taxes, and general transitioning towards a more sustainable society, drivers for WHR may well shift towards a mix of environmental and economic factors. As a result, sub-sectors with the largest annual $\mathrm{CO}_{2}$ abatement potential associated with their economic potential have been identified, along with rough estimates for economic savings through carbon tax avoidance. Again, for the main scenarios, the top five (which together account for around $5 \%$ of annual $\mathrm{CO}_{2}$ emissions) are the same as those listed as economic potential hotspots, but the order varies:

1. Road: $700-900 \mathrm{Mt}, \$ 14 \mathrm{bn}-\$ 18 \mathrm{bn}$ 
2. Iron and Steel: $200-300 \mathrm{Mt}, \$ 4 \mathrm{bn}-\$ 6 \mathrm{bn}$

3. Aircraft: $200-300 \mathrm{Mt}, \$ 4 \mathrm{bn}-\$ 6 \mathrm{bn}$

4. Non-Metallic Minerals: $200 \mathrm{Mt}, \$ 4 \mathrm{bn}$

5. Residential: $100-200 \mathrm{Mt}, \$ 2 \mathrm{bn}-\$ 4 \mathrm{bn}$

\subsection{Technical Considerations for Waste Heat Recovery}

While the derivation of a meaningful technical potential was considered beyond the scope of this study, an understanding of the practical aspects of WHR is essential to put the presented findings into context. This sub-section therefore aims to give an overview of major WHR technologies and applications, with a particular focus on the sub-sectors with the largest economic potentials. The theoretical potentials calculated in this study provide an upper bound for thermodynamically recoverable waste heat by assuming Carnot recovery efficiency. In practice, WHR technologies will operate at lower efficiencies, leading to a lower technical potential. Moreover, there are many practical considerations which may reduce recovery efficiencies or render recovery infeasible. These include the physical state and chemical composition of waste heat streams, space requirements, its availability and consistency, economies of scale and, material selection issues due to high temperatures, thermal cycling, or corrosion [31].

In their comprehensive 2008 study, the U.S Department of Energy identifies three stages of waste heat recovery: identification of sources, recovery technology, and uses for recovered waste heat [4]. The present study has focussed on the first of these stages by quantifying global waste heat sources. In literature, several categories of end-use applications have been identified, namely: electricity generation, space and water heating, industrial process heating and steam generation, or cooling $[32,33]$. Several typical recovery technologies are provided in Table 14 according to waste heat temperature range.

Table 14: Waste Heat Recovery technologies by temperature range [4, 31,34,35].

\begin{tabular}{|c|c|c|}
\hline $\begin{array}{c}\text { Low Temperature } \\
\left(<100^{\circ} \mathrm{C}\right)\end{array}$ & $\begin{array}{c}\text { Medium Temperature } \\
\left(100^{\circ} \mathrm{C}-300^{\circ} \mathrm{C}\right)\end{array}$ & $\begin{array}{c}\text { High Temperature } \\
\left(>300^{\circ} \mathrm{C}\right)\end{array}$ \\
\hline
\end{tabular}




\begin{tabular}{|c|c|c|}
\hline $\begin{array}{l}\text { - } \text { Heat Pumps } \\
\text { - } \quad \text { Absorption Coolers } \\
\text { - } \quad \text { Shell and tube heat } \\
\text { exchanger } \\
\text { - } \quad \text { Plate heat exchanger } \\
\text { - } \text { Heat Pumps } \\
\text { - } \quad \text { Thermoelectric } \\
\text { generation } \\
\text { - Condensing water } \\
\text { heaters }\end{array}$ & $\begin{array}{ll}\text { - } & \text { Organic Rankine Cycle } \\
\text { - } & \text { Kalina Cycle } \\
\text { - } & \text { Heat Pumps } \\
\text { - } & \text { Thermoelectric } \\
\text { generation } \\
\text { - } \quad \text { Metallic recuperators } \\
\text { - } \quad \text { Self-recuperative burners } \\
\text { - } \quad \text { Waste Heat Boilers } \\
\text { - } \quad \text { Heat pipe exchanger }\end{array}$ & $\begin{array}{l}\text { - } \quad \text { Regenerative and self- } \\
\text { recuperative burners } \\
\text { - Ceramic and metallic } \\
\text { regenerators and recuperators } \\
\text { - Steam Rankine Cycle } \\
\text { - Kalina Cycle } \\
\text { - Waste heat boilers }\end{array}$ \\
\hline
\end{tabular}

While WHR technologies may be generalised as above, specific applications within subsectors often require more tailored WHR solutions to be developed. Within the Road subsector, the largest hotspot identified in this study, EL is due to high-temperature exhausts and low-temperature liquid coolant in Internal Combustion Engines (ICEs). Two main technologies may be considered: bottoming cycles and thermoelectric generation. Bottoming cycles involve extracting thermal energy from the exhaust stream to power a thermodynamic cycle, typically an Organic Rankine Cycle (ORC). Significant thermal efficiency improvements have been reported $(10-15 \%$ for heavy-duty vehicles and around $5 \%$ for passenger vehicles [33]). However, space and weight constraints, as well as waste heat inconsistency, have limited the development of this technology [36]. Thermoelectric WHR converts thermal energy directly to electricity through the Seebeck effect [34]. While this offers significant advantages such as a solid-state, passive WHR system, material limitations have meant that current Coefficients of Performance are fairly low and maximum power outputs are of several hundred watts $[37,38]$. Turbocompounding, in which a turbine is used to extract energy from exhaust gases, may be considered a third main WHR technology as it causes a temperature drop despite being pressure-driven [39].

Similarly, to the Road sub-sector, the Aircraft sub-sector waste heat originates from the exhaust streams of a large number of point source combustion engines, but at higher temperatures. As a result, WHR systems in this sub-sector are also subject to stringent size and weight constraints, which may explain the relatively small number of aircraft WHR studies, and limits the feasibility of Rankine Cycles despite computational results suggesting 
possible fuel savings [40]. Thermoelectric generation is also limited by the need to maintain large temperature difference, requiring large heat exchanger areas for relatively low thermal efficiencies [6,7]. Due to the inherent limitations of aircraft WHR, fuel switching towards electric- or fuel cell-powered aircraft may be the most feasible way of reducing waste heat emissions, rather than WHR technology. This is corroborated by the increase in research into electrical and hybrid aircraft by both start-ups and established aviation companies in recent years [43].

Waste heat in the Non-Metallic minerals sub-sector is assumed to originate from the glass and cement industries, based on the work of Forman et al., and the consumption of energy within the sub-sector $[6,44]$. Both areas are characterised by high-temperature exhausts. In the cement industry, waste heat is contained in kiln exhaust gases and in the air used for clinker cooling. In the glass industry, waste heat originates from melting furnaces. While significant energy savings are possible in both industries, the capital costs of replacing existing machinery are thought to be a barrier to ubiquitous WHR [44]. WHR technology options are similar to those in the Road and Aircraft sub-sectors, but are not subject to stringent size and weight constraints. As a result, Steam Rankine Cycles (SRCs) and ORCs may be effectively used to generate electrical energy, with the former more efficient at higher temperatures. Karellas et al. state an output of $6 \mathrm{MW}$ for a typical cement plant, and find SRCs to be more efficient for exhaust temperatures above $310^{\circ} \mathrm{C}$, while Campana et al. estimate 1-2 MW for a number of EU glass plants of varying size using ORCs [45, 46]. In addition, heat exchangers may be used to preheat material. Regenerative or recuperative furnaces may be employed for such a purpose in the glass industry depending on scale, allowing potential WHR of $60-80 \%[4,34,47]$. Up to $75 \%$ of thermal energy contained within clinker cooling air may be recovered in the cement industry and used for combustion air preheating [34].

The high economic potential of the Iron and Steel sub-sector is due to high-temperature exhausts from blast and cupola furnaces, as well as electric arc furnaces. Currently, 
recuperators are used with blast and cupola furnace exhausts for preheating furnaces and combustion air, allowing significant energy savings [34]. Electric arc furnace exhaust gases may be used to preheat scrap in a charging bucket, or in more sophisticated designs such as the Fuchs shaft preheater which may reduce electricity consumption by up to $20 \%[4,34]$. While iron and steel exhaust streams are at high temperatures, they are also heavily contaminated, leading to high capital costs for WHR [4]. There is thus also significant chemical potential energy contained within these high-temperature exhausts which may be converted to thermal energy [34], but this type of energy is not considered within this study.

Unlike the other sub-sectoral hotspots, the Residential sub-sector is characterised by low- and medium-temperature waste heat streams. These are predominantly due fossil fuel and biomass burners used for space and water heating, with some additional contribution from electrical cooling and refrigeration units. Due to the waste heat temperatures and domestic end-use application temperatures, the use of heat exchangers on boiler flue gases for preheating domestic water and heating air is likely to represent the most appropriate technology. Fuel switching to electrical heating or heat pumps or implementation of district heating would be a more effective method of reducing waste heat emissions, although possibly more costly $[48,49,50]$. Additionally, the low-grade waste heat produced in the other sectors (e.g. industrial) can be utilized to satisfy the heating demand in the Residential sub-sector, thus displacing the fuel consumption and reducing the generated waste heat. This type of holistic energy systems integration has been studied as a part of the food-waterenergy nexus systems [51], however, is beyond the scope of this study. It should be reemphasised that this study only considers "active" energy conversion processes (see Section 2.1), and as such "passive" heat losses such as through poor insulation are not considered waste heat. Recovery of heat in vented air and utility water through heat exchangers and heat pumps, or insulation improvements would therefore not be classed as WHR in this context, but can allow significant savings in primary energy requirements. 


\subsection{Comparison with Other Studies}

\subsubsection{Waste Heat Quantification}

Results can be compared to the work of Forman et al. [6], upon whose methodology this investigation was based. The results of this work are over several years and scenarios, and are therefore given as a range, whereas those of Forman et al. [6] were only for the year 2014. In order to make a comparison, a small number of sub-sectors in Forman's study had to be moved between sectors. This was not expected to cause any major discrepancies.

Table 15: Comparison of Results With Forman et al. [6].

\begin{tabular}{|c|c|c|c|c|}
\hline \multirow{2}{*}{ Area } & \multicolumn{2}{|c|}{ EL Waste (\% Input) } & \multicolumn{2}{c|}{ Theoretical Potential (\% Input) } \\
\cline { 2 - 5 } & Forman et al. & This Work & Forman et al. & This Work \\
\hline Industry & $30 \%$ & $28-29 \%$ & $10 \%$ & $11-12 \%$ \\
\hline Transport & $59 \%$ & $57-59 \%$ & $21 \%$ & $22-23 \%$ \\
\hline Buildings & $34 \%$ & $32-34 \%$ & $8 \%$ & $8-9 \%$ \\
\hline $\begin{array}{c}\text { Power } \\
\text { Generation }\end{array}$ & $49 \%$ & $48-55 \%$ & $2 \%$ & $2-3 \%$ \\
\hline World & $52 \%$ & $49-53 \%$ & $10 \%$ & $12 \%$ \\
\hline
\end{tabular}

Table 15 shows results are very similar in all sectors and overall. The largest discrepancy

is in Power Generation sector EL waste, likely due to the modification to the methodology (see Section 2.3). Furthermore, theoretical potential results are consistently higher, probably due to the calculation of exergetic content being based on the HHV of fuels rather than the LHV. Due to the similarity of data and methodology, this similarity of results was expected.

Industrial Waste Heat (IWH) results are compared to those of previous studies in Table 16, and most are found to be similar to previous studies. Results would not be expected to be identical due to the broader nature of this study.

Table 16: Comparison of Industrial Waste Heat Results With Previous Studies

\begin{tabular}{|c|c|c|c|c|c|c|c|}
\hline \multirow{2}{*}{$\begin{array}{c}\text { Author } \\
\text { (Date) }\end{array}$} & \multirow{2}{*}{ Area } & \multicolumn{2}{|c|}{$\begin{array}{c}\text { EL } \\
\text { (\% Input) }\end{array}$} & \multicolumn{2}{c|}{$\begin{array}{c}\text { Theoretical } \\
\text { Potential } \\
\text { (\% Input) }\end{array}$} & \multicolumn{2}{c|}{$\begin{array}{c}\text { Economic } \\
\text { Potential } \\
\text { (\% Input) }\end{array}$} \\
\cline { 3 - 8 } & & Literature & $\begin{array}{c}\text { This } \\
\text { Study }\end{array}$ & Literature & $\begin{array}{c}\text { This } \\
\text { Study }\end{array}$ & Literature & $\begin{array}{c}\text { This } \\
\text { Study }\end{array}$ \\
\hline Energetics & U.S & $28 \%$ & $\begin{array}{c}28- \\
29 \%\end{array}$ & $7 \%$ & $11-$ & - & - \\
(2004) [52] & & & & - & - & - & - \\
\hline López & Basque & $41 \%$ & $28-$ & - & & - \\
(1996) [53] & Country & & $29 \%$ & & - & - & - \\
\hline Berthou & France & $26 \%$ & $28-$ & - & - & \\
\hline
\end{tabular}




\begin{tabular}{|c|c|c|c|c|c|c|c|}
\hline (2012) [54] & & & $29 \%$ & & & \\
\hline $\begin{array}{c}\text { U.S. DOE } \\
(2008)[4]\end{array}$ & U.S. & - & - & $18 \%$ & $\begin{array}{c}11- \\
12 \%\end{array}$ & - & - \\
\hline $\begin{array}{c}\text { Pehnt et al. } \\
(2011) \text { [55] }\end{array}$ & Germany & - & - & $18 \%$ & $\begin{array}{c}11- \\
12 \%\end{array}$ & - & - \\
\hline $\begin{array}{c}\text { EPA } \\
(1984)[26]\end{array}$ & $\begin{array}{c}\text { U.S. } \\
\text { Industry } \\
\text { and } \\
\text { Power) }\end{array}$ & $30 \%$ & $\begin{array}{c}40- \\
45 \%\end{array}$ & - & - & $3 \%$ & $4 \%$ \\
\hline $\begin{array}{c}\text { Persson et } \\
\text { al. (2014) } \\
{[56]}\end{array}$ & $\begin{array}{c}\text { EU } \\
\text { (Industry } \\
\text { and } \\
\text { Power) }\end{array}$ & $43 \%$ & $\begin{array}{c}40- \\
45 \%\end{array}$ & - & - & - & - \\
\hline
\end{tabular}

\subsubsection{Environmental Effects}

Comparison of environmental effects results with previous work is difficult: previous waste heat effects on global radiative forcing have not covered all sectors or fuel uses and have not considered future effects. Furthermore, much of the environmental effects results depend on the waste heat input data. As a result, it was decided that on the whole, direct numerical comparison would not provide much insight. Qualitatively, both the work of Zevenhoven, and Zhang and Caldeira found that the annual increase in waste heat radiative forcing is of similar magnitude to that of $\mathrm{CO}_{2}$ radiative forcing from the same sectors investigated, but that the latter rapidly becomes more important as $\mathrm{CO}_{2}$ emissions accumulate $[17,18]$. The findings from this work (see Section 3.2) are in-line with these previously obtained conclusions.

\subsection{Limitations and Future Work}

While the results obtained are clearly dependent on the accuracy of energy use predictions, this study introduces a framework for the estimation of future waste heat and its environmental effects. The methodology may be updated to reflect changes in the world energy landscape (i.e. through changes in balance factors), or may be applied to different sets of predictions. A number of areas have been identified for future improvements.

The method used for estimating future sub-sectoral data could be refined by switching to a more bottom-up approach. Energy flow data exists for individual countries and groupings 
of countries (e.g. OECD, Latin America) and the methodology employed in this study could thus be done on a much more localised basis, and results then aggregated to form a global estimate. Localised analyses would allow more specific balance factors to be used (including more projections of efficiency improvements, which are lacking in this study), permit identification of more precise hotspots (including geographic), and allow the effect on regional climate to be investigated.

A major limitation is the lack of in-built approach to deal with fuel switching: when switching from fuel 1 to fuel 2 for some function $X$ (e.g. smelting), the increase in fuel 2 will be distributed between all of the processes of fuel 2 , which may not fulfil function X. This could be solved by identifying functions within each sub-sector, determining processes for each viable fuel that can fulfil this function (including the associated balance factors and output temperatures), and ensuring that the same proportion of sub-sectoral input energy is used to fulfil each function. This limitation, along with the over-simplification of processes and conservative IEA estimates, may partly explain why results over time and between scenarios have had little variation. On the other hand, the methodology of the current work may be too coarse-grained for significant differences to emerge based on predicted changes to the fuel mix. The only case where fuel switching was accounted for rather precisely in this study was in the Buildings sector of the Aggressive scenario, where almost complete electrification of combustion processes was directly attributed to an increase in only electrical heating processes.

Finally, there is a lack of emphasis in this work on the feasibility of waste heat recovery, due to which a technical potential was not given. While supply and demand matching on a global scale is unfeasible, the creation of a sector-specific technology database with associated efficiencies and operating temperature ranges could be achieved. This would then allow the determination of a technical potential, as well as a more practical economic potential. The latter could be done using a general or a technology-specific cut-off temperature for economically recoverable waste heat. 


\section{Conclusions}

Waste heat represents a major source of global energy losses, with significant abatement potential. However, knowledge of the size and distribution of this resource is necessary to successfully target areas for recovery. Previous work on waste heat quantification is limited to specific sectors or geographic areas, and only considered the present-day without assessing its impact on the environment. This study reports a method to quantify current and future global waste heat production, and analyses its environmental effects. Various scenarios predicting the global energy outlook in 2030 (the CP, NP and 450 scenarios from WEO2016 [15]) were simulated to show the waste heat produced in key sectors, i.e. Buildings, Industry, Transport, and Power Generation. Process-specific balance factors and fuel-specific efficiency factors were applied to the IEA energy flow data. This allowed the proportions of useful energy output, waste heat output, and other losses output to be determined. Waste heat predictions were used to estimate the environmental impact of waste heat, particularly in terms of radiative forcing. The impact of potential key shifts (i.e. greater renewable energy integration, CCS implementation, elevated EV penetration) in the energy sector were estimated and discussed.

The quantity of waste heat was found to be significant in all scenarios and years, accounting for $23-53 \%$ of global input energy. This led to a global theoretical WHR potential of $6-12 \%$, and an economic potential of $6-9 \%$. In the three main scenarios investigated, results showed comparatively little variation in waste heat production (relative to input) over time and between scenarios. This similarity indicates that the most effective way of limiting absolute waste heat emissions is through an overall reduction in energy use rather than realistic fuel switching. The distribution of the theoretical potential demonstrates a clear need for effective medium-temperature $\left(100^{\circ} \mathrm{C}-300^{\circ} \mathrm{C}\right) \mathrm{WHR}$, with $38-63 \%$ of the theoretical potential being in this temperature band. The Transport sector was found to be the largest 
untapped sector for recoverable waste heat in the three main scenarios, with $43-44 \%$ of the global theoretical potential, and an economic potential estimated at around $4 \%$ of global energy consumption. The Power Generation sector was found to be very inefficient in the three main scenarios, with thermodynamic limitations and low effluent temperatures leading to high EL production $(42-45 \%$ of global) but a low theoretical WHR potential $(8-10 \%$ of global). In the three main scenarios, a $10 \%$ increase in the proportion of total power generated by solar/wind/tidal/hydroelectric at the expense of non-CCS fossil-fuels was found to decrease global EL by $5 \%$ and increase global efficiency by around $2 \%$ (in absolute terms). A $10 \%$ absolute increase in the market share of EVs (i.e. from around $0.2 \%$ to $10.2 \%$ [57]) was found to decrease global EL by $0.7-1.1 \%$ and increase global efficiency by around $0.2 \%$ (in absolute terms), if the existing fuel mix provided the extra electricity. If the extra electricity were generated by solar/wind/tidal/hydroelectric, these figures were effectively doubled.

Radiative forcing of the annual waste heat emissions was found to be $70-85 \%$ of that caused by annual $\mathrm{CO}_{2}$ emissions in the main scenarios. However, the cumulative nature of atmospheric $\mathrm{CO}_{2}$ meant that by 2030 , annual $\mathrm{CO}_{2}$ forcing due only to post-2013 emissions was 20-22 times larger than that of waste heat. Furthermore, when integrating this forcing over time to gain insight into the overall effect on the planet over 16 years, $\mathrm{CO}_{2}$ forcing was found to be 13 times more important than that of waste heat, with this ratio increasing over time. Avoidable $\mathrm{CO}_{2}$ through full recovery of the theoretical potential was found to correspond to $10-19 \%$ of global emissions in all scenarios and years. When considering the reduction in radiative forcing associated with this recovery, it was found that the majority of the abatement effect (around 85\%) was through the reduction in $\mathrm{CO}_{2}$ emissions as opposed to the avoidance of waste heat released. The potential economic savings from this reduced $\mathrm{CO}_{2}$ were estimated at $\$ 20-77 \mathrm{bn}$ per year with a conservative carbon tax at $\$ 20 /$ tonne. 
Overall, waste heat has been shown to be a significant source of inefficiency in present and future society, providing scope for considerable reductions in energy use and $\mathrm{CO}_{2}$ emissions. It is hoped that this study will be the basis for further global waste heat investigations, with the ultimate aim being to impact the direction of energy policy and technological innovation. 


\section{References}

[1] J. M. Cullen and J. M. Allwood, "Theoretical efficiency limits for energy conversion devices," Energy, vol. 35, no. 5, pp. 2059-2069, May 2010.

[2] S. Brueckner, L. Miró, L. F. Cabeza, M. Pehnt, and E. Laevemann, "Methods to estimate the industrial waste heat potential of regions - A categorization and literature review," Renew. Sustain. Energy Rev., vol. 38, pp. 164-171, Oct. 2014.

[3] L. Miró, S. Brückner, and L. F. Cabeza, "Mapping and discussing Industrial Waste Heat (IWH) potentials for different countries," Renew. Sustain. Energy Rev., vol. 51, pp. 847-855, Nov. 2015.

[4] U.S. Department of Energy, "Waste Heat Recovery: Technology and Opportunities in U.S. Industry," 2008. [Online]. Available:

https://www1.eere.energy.gov/manufacturing/intensiveprocesses/pdfs/waste_heat_reco very.pdf. [Accessed: 31-Mar-2017].

[5] N. Nakićenović, P. V. Gilli, and R. Kurz, "Regional and global exergy and energy efficiencies," Energy, vol. 21, no. 3, pp. 223-237, Mar. 1996.

[6] C. Forman, I. K. Muritala, R. Pardemann, and B. Meyer, "Estimating the global waste heat potential," Renew. Sustain. Energy Rev., vol. 57, pp. 1568-1579, May 2016.

[7] IPCC, "Climate Change 2013: The Physical Science Basis. Contribution of Working Group I to the Fifth Assessment Report of the Intergovernmental Panel on Climate Change," 2013.

[8] M. G. Flanner, "Integrating anthropogenic heat flux with global climate models," Geophys. Res. Lett., vol. 36, no. 2, p. L02801, Jan. 2009.

[9] R. Zevenhoven and A. Beyene, "The relative contribution of waste heat from power plants to global warming," Energy, vol. 36, no. 6, pp. 3754-3762, Jun. 2011.

[10] X. Zhang and K. Caldeira, "Time scales and ratios of climate forcing due to thermal versus carbon dioxide emissions from fossil fuels," Geophys. Res. Lett., vol. 42, no. 11, p. 2015GL063514, Jun. 2015.

[11] H. Lu, "Capturing the Invisible Resource. Analysis of Waste Heat Potential in Chinese Industry and Policy Options for Waste Heat to Power Generation," Lawrence Berkeley National Laboratory (LBNL), Berkeley, CA (United States), LBNL--179618, May 2015.

[12] UK Department of Energy and Climate Change, "The Potential for Recovering and Using Surplus Heat from Industry," 2014.

[13] "IEA Sankey Diagram." [Online]. Available: https://www.iea.org/sankey/\#?c=World\&s=Balance. [Accessed: 08-Jan-2017].

[14] United Nations, "International Standard Industrial Classification of All Economic Activities (ISIC), Revision 4," 20008.

[15] IEA, World Energy Outlook 2016. Paris, France, 2016.

[16] M. Z. Jacobson and M. A. Delucchi, "Providing all global energy with wind, water, and solar power, Part I: Technologies, energy resources, quantities and areas of infrastructure, and materials," Energy Policy, vol. 39, no. 3, pp. 1154-1169, Mar. 2011.

[17] M. A. Delucchi and M. Z. Jacobson, "Providing all global energy with wind, water, and solar power, Part II: Reliability, system and transmission costs, and policies," Energy Policy, vol. 39, no. 3, pp. 1170-1190, Mar. 2011.

[18] X. D. Peng, "Analysis of the Thermal Efficiency Limit of the Steam Methane Reforming Process," Ind. Eng. Chem. Res., vol. 51, no. 50, pp. 16385-16392, Dec. 2012.

[19] J. D. Holladay, J. Hu, D. L. King, and Y. Wang, "An overview of hydrogen production technologies," Catal. Today, vol. 139, no. 4, pp. 244-260, Jan. 2009.

[20] R. A. Gordon, Applied Statistics for the Social and Health Sciences. Routledge, 2012.

[21] C. Le Quéré, "Trends in the land and ocean carbon uptake," Curr. Opin. Environ. Sustain., vol. 2, no. 4, pp. 219-224, Oct. 2010.

[22] C. D. Jones and P. M. Cox, "On the significance of atmospheric $\mathrm{CO} 2$ growth rate anomalies in 2002-2003," Geophys. Res. Lett., vol. 32, no. 14, p. L14816, Jul. 2005. 
[23] S. User, "Annual CO2 Data," CO2.Earth. [Online]. Available: https://www.co2.earth/annual-co2. [Accessed: 31-Mar-2017].

[24] I. S. Ertesvåg and M. Mielnik, "Exergy analysis of the Norwegian society," Energy, vol. 25, no. 10, pp. 957-973, Oct. 2000.

[25] N. M. Haegel et al., "Terawatt-scale photovoltaics: Trajectories and challenges," Science, vol. 356, no. 6334, pp. 141-143, Apr. 2017.

[26] EPA, "Industrial Waste Heat Recovery and the Potential for Emissions Reduction," 1984.

[27] D. Grover, G. Shreedhar, and D. Zenghelis, "The competitiveness impact of a UK carbon price: what do the data say?," 2016.

[28] K. Z. House, C. F. Harvey, M. J. Aziz, and D. P. Schrag, "The energy penalty of postcombustion $\mathrm{CO} 2$ capture \& storage and its implications for retrofitting the U.S. installed base," Energy Env. Sci, 2009.

[29] S. S. IEA, "Technology Roadmap: Fuel Cells and Hydrogen," 2015.

[30] A. Roy, S. Watson, and D. Infield, "Comparison of electrical energy efficiency of atmospheric and high-pressure electrolysers," Int. J. Hydrog. Energy, vol. 31, no. 14, pp. 1964-1979, Nov. 2006.

[31] EPA, "Waste Heat To Power Systems," 2012.

[32] R. Suryavanshi and A. D. Pitale, "A Review on Waste Heat Recovery in Industries," Int. Jourmal Res. Advent Technol., vol. 4, no. 5, Apr. 2017.

[33] D. Sjoding, "Overview of waste heat recovery for power and heat," Chic. Northwest Clean Energy Appl. Cent. Wash. State Univ. Ext. Energy Program, 2010.

[34] S. Nimbalkar and A. Thekdi, "Technologies and Materials for Recovering Waste Heat in Harsh Environments," Oak Ridge National Laboratory, 2014.

[35] U.S. Department of Energy, "An Assessment of Energy Technologies And Research Opportunities," 2015.

[36] F. Zhou, S. N. Joshi, R. Rhote-Vaney, and E. M. Dede, "A review and future application of Rankine Cycle to passenger vehicles for waste heat recovery," Renew. Sustain. Energy Rev., vol. 75, pp. 1008-1021, Aug. 2017.

[37] B. Orr, A. Akbarzadeh, M. Mochizuki, and R. Singh, "A review of car waste heat recovery systems utilising thermoelectric generators and heat pipes," Appl. Therm. Eng., vol. 101, pp. 490-495, May 2016.

[38] J. Yang, "Potential applications of thermoelectric waste heat recovery in the automotive industry," in ICT 2005. 24th International Conference on Thermoelectrics, 2005. Clemson, SC, USA, 2005, pp. 170-174.

[39] C. Copeland, A. Pesiridis, R. Martinez-Botas, S. Rajoo, A. Romagnoli, and A. Mamat, "Automotive Exhaust Waste Heat Recovery Technologies," Automot. Exhaust Emiss. Energy Recovery, 2014.

[40] S. Saadon, "Computational modelling of an Organic Rankine Cycle (ORC) waste heat recovery system for an aircraft engine," MATEC Web Conf., vol. 151, p. 2001, 2018.

[41] V. D. L. (Victoria D. Lee, "Waste heat reclamation in aircraft engines," Thesis, Massachusetts Institute of Technology, 2014.

[42] K. Cheng et al., "Performance Evaluation of Waste Heat Recovery Systems Based on Semiconductor Thermoelectric Generators for Hypersonic Vehicles," Energies, vol. 10, no. 4, p. 570, Apr. 2017.

[43] Roland Berger, "Aircraft Electrical Propulsion - The Next Chapter of Aviation?," 2017.

[44] E. Efficiency, "Tracking Industrial Energy Efficiency and CO2 Emissions," Int. Energy Agency, vol. 34, no. 2, pp. 1-12, 2007.

[45] S. Karellas, A.-D. Leontaritis, G. Panousis, E. Bellos, and E. Kakaras, "Energetic and exergetic analysis of waste heat recovery systems in the cement industry," Energy, vol. 58, pp. 147-156, Sep. 2013.

[46] F. Campana et al., "ORC waste heat recovery in European energy intensive industries: Energy and GHG savings," Energy Convers. Manag., vol. 76, pp. 244-252, Dec. 2013.

[47] G. Dolianitis et al., "Waste heat recovery at the glass industry with the intervention of batch and cullet preheating," Therm. Sci., vol. 20, pp. 79-79, Jan. 2016. 
[48] O. Gudmundsson, J. E. Thorsen, and L. Zhang, "Cost analysis of district heating compared to its competing technologies," presented at the ENERGY AND SUSTAINABILITY 2013, Bucharest, Romania, 2013, pp. 3-13.

[49] C. N. Markides, "The role of pumped and waste heat technologies in a high-efficiency sustainable energy future for the UK," Appl. Therm. Eng., vol. 53, no. 2, pp. 197-209, May 2013.

[50] M. Sørensen Torekov, N. Bahnsen, and B. Qvale, "The relative competitive positions of the alternative means for domestic heating," Energy, vol. 32, no. 5, pp. 627-633, May 2007.

[51] U.S. Department of Energy, "The Water-Energy Nexus: Challenges and Opportunities," 2014.

[52] Energetics Incorporated, "Opportunity Analysis for Recovering Energy from Industrial Waste Heat and Emissions," Research Gate, 2004. [Online]. Available: https://www.researchgate.net/publication/255242653_Opportunity_Analysis_for_Recov ering_Energy_from_Industrial_Waste_Heat_and_Emissions. [Accessed: 31-Mar-2017].

[53] L. López, J. M. Blanco, J. J. Bonilla, S. Bacza, and J. M. Sala, "Determination of energy and exergy of waste heat in the industry of the Basque country," Appl. Therm. Eng., vol. 18, no. 3, pp. 187-197, Mar. 1998.

[54] M. Berthou, "Overview of Waste Heat in the Industry in France," in Proceedings of the ECEEE 2012, 2012.

[55] M. Pehnt, "Industrial Waste Heat - Tapping Into a Neglected Efficiency Potential," in Proceedings of ECEEE 2011, 2011.

[56] U. Persson, B. Möller, and S. Werner, "Heat Roadmap Europe: Identifying strategic heat synergy regions," Energy Policy, vol. 74, pp. 663-681, Nov. 2014.

[57] IEA, "Global EV Outlook 2017," 2017.

[58] EPA, "Greenhouse Gas Inventory Guidance - Direct Emissions from Mobile Combustion Sources," 2016. [Online]. Available: https://www.epa.gov/sites/production/files/201603/documents/mobileemissions_3_2016.pdf. [Accessed: 31-Mar-2017].

[59] Department for Business, Energy \& Industrial Strategy, "Estimated average calorific values of fuels," 2015. [Online]. Available:

https://www.gov.uk/government/statistics/dukes-calorific-values. [Accessed: 31-Mar2017].

[60] Food and Agriculture Organization of the United Nations, "OECD-FAO Agricultural Outlook 2015-2024," 2015. [Online]. Available: http://www.fao.org/3/a-i4738e.pdf. [Accessed: 31-Mar-2017].

[61] M. C. Rodríguez-Hidalgo, P. A. Rodríguez-Aumente, A. Lecuona, G. L. GutiérrezUrueta, and R. Ventas, "Flat plate thermal solar collector efficiency: Transient behavior under working conditions. Part I: Model description and experimental validation," Appl. Therm. Eng., vol. 31, no. 14-15, pp. 2394-2404, Oct. 2011.

[62] "Improving IC Engine Efficiency." [Online]. Available: http://courses.washington.edu/me341/oct22v2.htm. [Accessed: 31-Mar-2017].

[63] IEA, "Technology Roadmap: Fuel Economy of Road Vehicles," 2012. [Online]. Available: https://www.iea.org/publications/freepublications/publication/technologyroadmap-fuel-economy-of-road-vehicles.html. [Accessed: 31-Mar-2017].

[64] "Efficiency classes for IEC line motors - Drive Technology - Siemens." [Online]. Available: http://www.industry.siemens.com/drives/global/en/motor/low-voltagemotor/efficiency-standards/pages/line-motors.aspx. [Accessed: 31-Mar-2017].

[65] R. Saidur, "A review on electrical motors energy use and energy savings," Renew. Sustain. Energy Rev., vol. 14, no. 3, pp. 877-898, Apr. 2010.

[66] Hemls, "Electric Vehicle and Plug-In Hybrid Efficiency and Life Cycle Emissions," presented at the 18th International Symposium Transport and Air Pollution, 2010.

[67] "Electric Vehicle Battery Thermal Issues and Thermal Management Techniques (Presentation), NREL (National Renewable Energy Laboratory) - 52818.pdf." [Online]. Available: http://www.nrel.gov/docs/fy13osti/52818.pdf. [Accessed: 31-Mar-2017]. 
[68] S. Swedenborg, Modeling and Simulation of Cooling System for Fuel Cell Vehicle. 2017.

[69] "Energy Efficiency Indicators." [Online]. Available: https://www.worldenergy.org/data/efficiency-indicators/. [Accessed: 31-Mar-2017].

[70] "Energy Efficiency for Power Plant Auxiliaries-V2_0.pdf." [Online]. Available: https://library.e.abb.com/public/5e627b842a63d389c1257b2f002c7e77/Energy\%20Effic iency\%20for\%20Power\%20Plant\%20Auxiliaries-V2_0.pdf. [Accessed: 31-Mar-2017].

[71] L. M. Romeo, I. Bolea, Y. Lara, and J. M. Escosa, "Optimization of intercooling compression in CO2 capture systems," Appl. Therm. Eng., vol. 29, no. 8-9, pp. 17441751, Jun. 2009. 


\section{Appendix}

\section{A-1: Deriving EL Balance Factor Based on HHV}

For clarity, the following terms are used in Appendix A-1:

- $U_{L H V}$ : the input energy to a process based on the input fuel's Lower Heating Value $(\mathrm{LHV})$

- $U_{H H V}$ : the input energy to a process based on the input fuel's Higher Heating Value (HHV)

- ELLHV : the energetic content of a process waste heat stream, based on the LHV of the input fuel of the process concerned

- ELHHV : the energetic content of a process waste heat stream, based on the HHV of the input fuel of the process concerned

There was only one major change to the general methodology of Forman et al. [6], which is related to the difference in Lower Heating Value (LHV) and Higher Heating Value (HHV) of combustion fuels. Both quantities represent the amount of heat released during complete combustion of a fuel at standard conditions, with all products are brought back to reactant temperature. However, the LHV does not include the heat of water vapour, whereas the HHV does. In this study, a waste heat stream's exergetic content is determined by applying the Carnot efficiency to its energetic content, i.e. calculations are based on the maximum thermodynamically extractable energy by cooling the stream to the environmental temperature $\left(25^{\circ} \mathrm{C}\right)$ and should thus include the aforementioned heat of condensation. To maintain consistency, ELHHV is adopted to quantify the amount of waste rather than ELLHV.

Upon comparison of the volume of each fossil fuel used and of the corresponding energy ascribed, it was noticed that energy flow values used by the IEA were based on the LHV of fuels. Therefore, all process inputs corresponded to $U_{L H V}$ rather than $U_{H H V}$. For any process, considering $\mathrm{U}_{\mathrm{HHV}}$ rather than the $\mathrm{U}_{\mathrm{LHV}}$ does not affect the process itself: the $\mathrm{ES}$ and $\mathrm{OL}$ 
remain unchanged, but the quantity of EL resulting from energy balance increases (from ELLHV to ELHHV). As a result, balance factors developed for $U_{L H V}$ cannot be used directly on $U_{H H V}$. Since all IEA energy flows are in terms of fuels' LHV, it was assumed that the balance factors obtained from literature $\left(\eta_{\mathrm{es}} / \eta_{\mathrm{el}} / \eta_{\mathrm{ol}}\right)$ were developed for $U_{\mathrm{LHV}}$. Therefore, when calculating a stream's ELHнv, one cannot simply apply the existing $\eta_{\mathrm{el}}$ balance factors to $\mathrm{U}_{H H V}$.

Instead, an 'ELHнv balance factor', $\eta_{\mathrm{el}, \mathrm{HHV}}$, was derived through conservation of energy, taking LHV:HHV ratios from literature $[31,32,33]$.

$$
\eta_{\mathrm{el}, \mathrm{HHV}}=\left(\eta_{\mathrm{el}}+\frac{\mathrm{HHV}-\mathrm{LHV}}{\mathrm{LHV}}\right)
$$

For convenience, this balance factor was designed to be applied to $U_{L H V}$, yielding $E L_{H H V}$ :

$$
E L_{H H V}=\eta_{\mathrm{el}, H H V} \times U_{L H V}
$$

\section{A-2: Updated End-Use Balance Factors}

Certain balance factors have been updated from the work of Forman et al, and are given in Table A1.

\begin{tabular}{|c|c|c|}
\hline Process & Old Factors ( $\left.\eta_{\text {es }}, \eta_{\text {el }}, \eta_{\mathrm{ol}}\right)(\%)$ & $\begin{array}{c}\text { New Factors }\left(\eta_{\text {es, }} \eta_{\text {el, }}, \eta_{\mathrm{ol}}\right)(\%) \text {, } \\
\text { Source of Data }\end{array}$ \\
\hline $\begin{array}{l}\text { Solar/Wind/Tidal Inputs } \\
\text { to Building sector }\end{array}$ & $100,0,0$ & $(60,0,40), \quad([61],[\mathrm{A}],[\mathrm{B}])$ \\
\hline Petrol Engine & $13,62,65$ & $(15,60,25), \quad([62],[63],[\mathrm{B}])$ \\
\hline 2020 & - & $(16,59,25), \quad([E],[E],[E])$ \\
\hline 2030 & - & $(17,59,24), \quad([E],[E],[E])$ \\
\hline Diesel Engine & $22,58,20$ & $(19,60,21), \quad([\mathrm{C}],[\mathrm{C}],[\mathrm{C}])$ \\
\hline 2020 & - & $(20,59,21), \quad([E],[E],[E])$ \\
\hline 2030 & - & $(21,59,21), \quad([E],[E],[E])$ \\
\hline Electric Motor & $60,30,10$ & $(90,7,3), \quad([13,37,38],[\mathrm{B}])$ \\
\hline 2020 & - & $(91,6,3), \quad([E],[E],[E])$ \\
\hline 2030 & - & $(93,5,2), \quad([E],[E],[E])$ \\
\hline Electric Vehicle & $60,30,10$ & $(73,6,21), \quad([66],[67],[\mathrm{B}])$ \\
\hline 2020 & - & $(74,6,20), \quad([E],[E],[E])$ \\
\hline 2030 & - & $(74,6,20),([E],[E],[E])$ \\
\hline $\begin{array}{l}\text { Fuel } \quad \text { Cell } 2014 \\
\text { Electric Vehicle }\end{array}$ & - & $(36,34,30), \quad([61],[[67], 62],[B])$ \\
\hline
\end{tabular}

Table A1: Changes to Balance Factors 


\begin{tabular}{|r|c|c|}
\hline 2020 & - & $(36,34.30), \quad([\mathrm{E}],[\mathrm{E}],[\mathrm{E}])$ \\
\hline 2030 & - & $(37,33.30), \quad([\mathrm{E}],[\mathrm{E}],[\mathrm{E}])$ \\
\hline
\end{tabular}

[A]: Assumption; [B]: Energy Balance; [C]: Calculation; [E]: Estimation (trend/scale available). Adapted from [6].

\section{A-3: Estimating Future End-Use Sub-Sectoral Data}

Estimated future data was subject to two constraints of varying importance:

1. For each fuel, the sum of sub-sectoral inputs had to equal the total sectoral input (as given by the IEA).

2. The future splits of the overall sectoral energy (i.e. not fuel-specific) between subsectors, and of sub-sectoral energy between different fuels, were expected to be roughly similar to those predicted by trend extrapolation (implying some continuity between historical data and estimated future data). This constraint was less strict because variation of energy splits was to be expected, and was therefore used more as a starting point and for guidance.

Due to the large number of variables involved compared to the number of constraints, there were too many degrees of freedom to analytically find a solution satisfying both constraints.

The extrapolation method detailed in Section 2.2 was used to generate initial estimates of future sub-sectoral fuel splits, as well as future sub-sectoral overall energy inputs (i.e. Constraint 2). Combining these two pieces of information allowed fuel-specific sub-sectoral inputs to be determined. This is a preliminary estimate of the required future sub-sectoral energy flow data.

However, since this preliminary estimate is based on Constraint 2, it will almost invariably violate Constraint 1 . The error with regard to Constraint 1 can be quantified for each fuel input to the sector. This was done by comparing the estimated sectoral input (i.e. the sum of the fuel's sub-sectoral inputs) with the IEA's predicted input. The data can be made to meet Constraint 1 by normalising each fuel-specific sub-sectoral input by its fuel's error. In turn, 
this will lead to a violation of Constraint 2. However, this constraint is not absolute, instead serving as guidance. The degree of deviation from Constraint 2 can be considered some measure of consistency with past data.

The overall process is presented graphically and mathematically in Fig. A1, where the symbols have the following meanings:

- E: vector representing fuel-specific inputs to sector

- $\lambda$ : matrix representing fuel split ratios within different sub-sectors

- i: vector representing total inputs to different sub-sectors

- e: matrix representing fuel-specific inputs to different sub-sectors, which is the ultimate energy flow data required for waste heat quantification

Superscript " " refers to a value that has been found through extrapolation and does not necessarily meet Constraint 1 . Subscripts are matrix and vector indices, with $s$ and $f$ referring to the sub-sector and fuel dimensions respectively, such that:

$$
\sum_{s} e_{s, f}=E_{f}, \sum_{f} \lambda_{s, f}=1 \text { and } \sum_{f} E_{f}=\sum_{s} i_{s}
$$




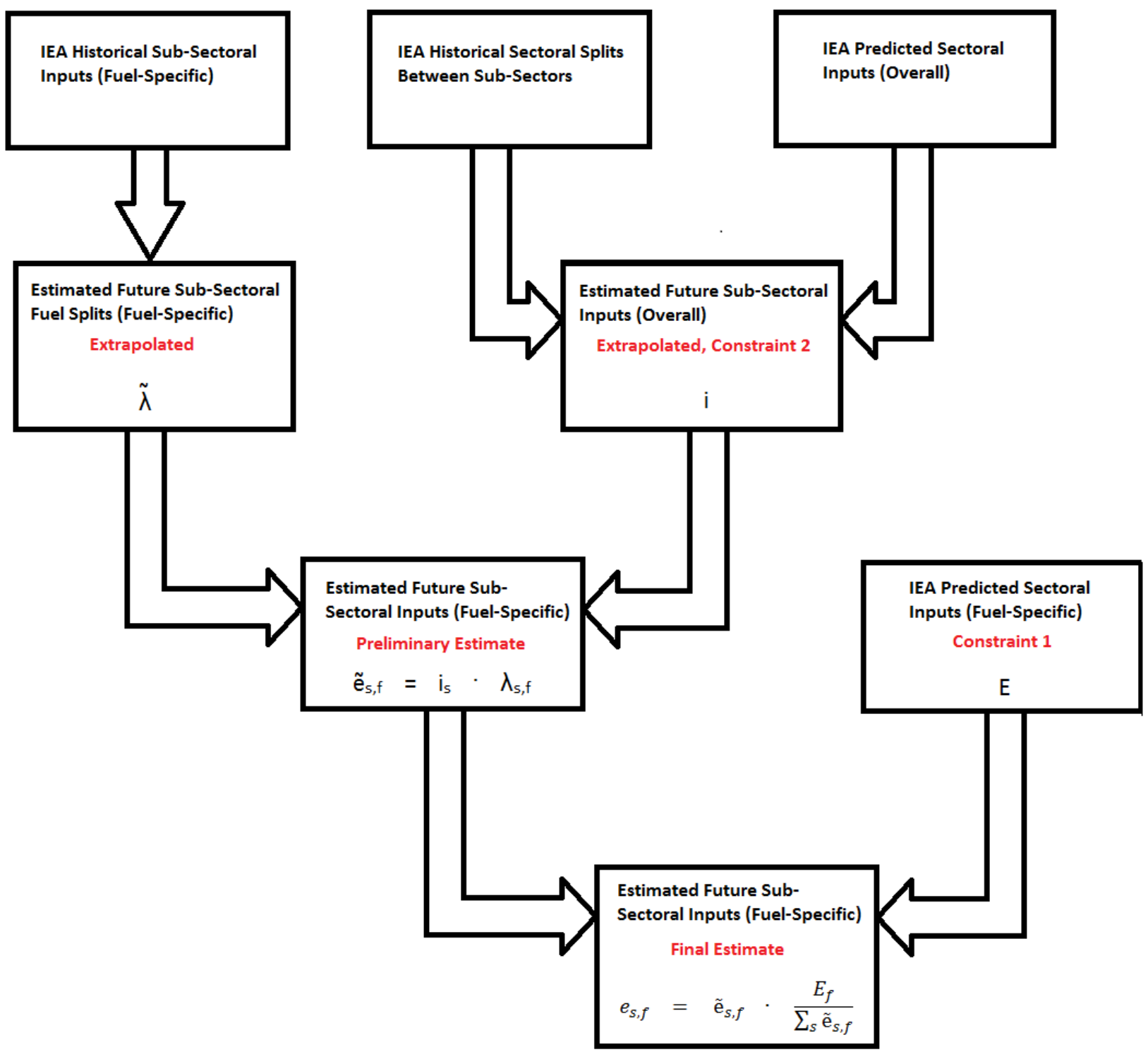

Figure A1: Graphical and mathematical representation of the process for obtaining future fuel-specific, sub-sectoral energy flow data

There were two cases where the general methodology presented above had to be adapted. Firstly, for Transport sector in the New Policies and 450 scenarios, the WEO provided all required splits for the year 2040. Linear interpolation was then performed between 2014 and 2040 data to estimate data for 2020 and 2030, and these figures were normalised to fit Constraint 1.

Secondly, as mentioned in Section 2.1.2, the Agriculture and Forestry, and Fishing subsectors were added to the Industry sector despite not being part of it in the WEO data. As a 
result, Constraint 1 was not applicable, and data was estimated independently of the rest of the sector. Total input to the Agriculture and Forestry sub-sector was estimated using the correlation between sub-sectoral input and Total Final Consumption, with a correlation factor found to be above 0.9 over the past 10 years. Total input to the Fishing sub-sector displayed no significant correlations over the past 10 years, and the F-test concluded that linear extrapolation of values was not appropriate. As a result, the 10-year mean of the the total energy input was used for future data. Fuel splits within both sub-sectors were linearly extrapolated using the usual first-order method.

\section{A-4: Estimating Future Power Generation Data}

The data used for the power generation balance factors is in a slightly different format to other sectors, and as a result the methodology used is also slightly different. There are 3 areas of loss: thermodynamic losses during the power generation cycle, auxiliary losses (including electricity needed to run the pumps, compressors, etc.), and transmission and distribution losses. The first of these was taken to constitute EL, while the latter two were combined to make up OL.

These three losses are defined in different ways in different sources. For example: auxiliary losses may be defined with respect to power plant input, or with respect to power plant net output. In this work, the following definitions were adopted based on the data used:

- Generation efficiency $\left(\eta_{\text {gen }}\right)$ : the ratio of net energy output from the plant to energy input, thus encompassing auxiliary losses.

- $\quad$ The Transmission and Distribution Losses rate $\left(\eta_{T \& D}\right)$ : the ratio of energy lost during transmission and distribution to final energy use.

- The Auxiliary Losses rate $\left(\eta_{\text {aux }}\right)$ : the ratio of auxiliary losses to total generated energy

The definitions used in this study meant that losses had to be calculated in 4 steps rather than 1, shown graphically in Fig. A2. 
1. $\eta_{\text {gen }}$ was applied to input data, giving the net power output from the plant, taking into account auxiliary losses.

2. Auxiliary losses were determined using Eq. A.5, noting that Auxiliary Losses can be expressed as a function of Total Generated Power via $\eta_{\text {aux. }}$

Net Plant Output $=$ Total Generated Power- Auxiliary Losses

3. Exhaust/effluent losses were calculated. These were assumed to correspond solely to the thermodynamic losses during the power generation cycle, and so were found approximately using Eq. A.6.

$$
\mathrm{EL}=\text { Energetic Content of Input Fuel - Total Power Generated }
$$

4. Transmission and distribution losses were calculated using Eq. A.7, noting that Transmission/Distribution Losses can be expressed as a function of Final Energy Use via $\eta_{T \& D}$. The net output of the plant contains both transmission losses and final energy use.

Net Plant Output $=$ Final Energy Use + Transmission/Distribution Losses

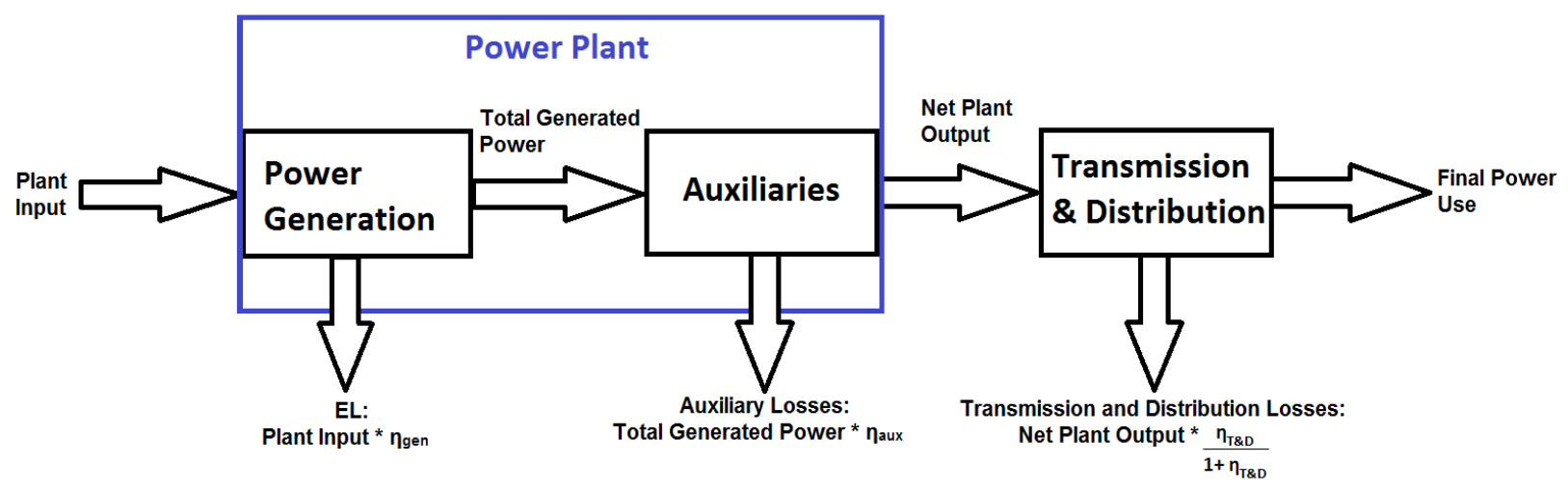

Figure A2: The updated approach to Power Generation waste heat

In the IEA data, "solar/wind/tide" and hydroelectric data are given as the value of generated electricity, and therefore have no quantified losses associated with generation. Thus, the only losses for these fuels were due to transmission and distribution.

\section{A-5: Updated Power Generation Balance Factors}


Certain balance factors for power generation process adopted by Forman et al. were updated for a number of reasons.

- Power plant efficiencies and average transmission loss rate were updated to 2014 data from the same WEC source [69].

- Auxiliary losses were raised from $3 \%$ of power plant input to $10 \%$ of total generated power based on more recent findings [70].

- It was found appropriate to associate hydroelectric power with no EL. This is because the IEA energy flow data is already in terms of net generated power, therefore corresponding to an $\eta_{\mathrm{el}}$ of 0 . The previous value $\eta_{\mathrm{el}}$ of $8.1 \%$ appeared not to have taken this into account, and may have been due to an erroneous stated effluent temperature of $80^{\circ} \mathrm{C}$.

The balance factors $\eta_{\text {gen }}$ (for fossil-fuel fired plants) and $\eta_{T \& D}$ were updated for 2020 and 2030 to reflect improving efficiency of generation and transmission. This was done using data from the WEC, who also provide the average annual compound growth in each value from 2000 to 2014. This growth was assumed to continue from 2014 to 2030 .

Carbon Capture and Storage (CCS) in gas and coal-fired plants was included by the WEO in the 450 scenario. This process required new balance factors. The $\mathrm{CO}_{2}$ capture process was assumed to be post-combustion, using MonoEthanol Amine (MEA) as a solvent. Three areas of heat loss, were analysed as part of $\mathrm{CO}_{2}$ capture and storage:

- Heating of the rich MEA, and generation of steam to regenerate the solvent and liberate the $\mathrm{CO}_{2}$. Values for the reboiler duty were calculated following the approach of House et al, using a stripper temperature of $390 \mathrm{~K}$ and an absorber temperature of $310 \mathrm{~K}$, and assuming no heat integration [28]. The balance factors used were those of Forman et al. for a coal burner and gas burner for coal-fired and gas-fired plants respectively [6]. 
- Cooling of the captured $\mathrm{CO}_{2}$ from the stripper temperature to $40^{\circ} \mathrm{C}$, assumed to be carried out by cooling water with an effluent temperature of $85^{\circ} \mathrm{C}$, with an $87 \%$ efficient heat exchanger (both typical values used in the work of Forman et al. [6])

- $\mathrm{CO}_{2}$ compression. This was assumed to involve 4-stage isentropic compression with isentropic efficiency of $65 \%$ and mechanical efficiency of $100 \%$ (as in $[66,67]$ ), from 1 bar to 110 bar with intercooling to $40^{\circ} \mathrm{C}$ in order to avoid the saturation region. Using the change in enthalpy over each compression and cooling stage, the total work required and heat released were calculated. $85^{\circ} \mathrm{C}$ cooling water effluent temperature was assumed, with an $87 \%$ efficient heat exchanger.

Values for the required work for injection of $\mathrm{CO}_{2}$ into a saline aquifer were taken from the study of House et al. [28]. 